CUADERNOS DE ESTUDIOS GALLEGOS, LXII Núm. 128 (enero-diciembre 2015), págs. 175-206

ISSN: $0210-847 \mathrm{X}$

DOI: 10.3989/ceg.2015.128.06

\title{
APORTACIÓN A LA FARMACOTERAPIA DEL SIGLO XVIII: EL RECETARIO MÉDICO DE ANSELMO ARIAS TEIXEIRO
}

\author{
Miguel Álvarez Soaje
}

Farmacéutico comunitario 


\section{APORTACIÓN A LA FARMACOTERAPIA DEL SIGLO XVIII: EL RECETARIO MÉDICO DE ANSELMO ARIAS TEIXEIRO}

\section{RESUMEN}

Entre una serie de manuscritos del siglo XVIII atribuidos a Anselmo Arias Teixeiro hemos localizado el documento que presentamos en esta investigación, un conjunto heterogéneo de recetas destinadas a un público con escasos recursos económicos. Se trata de un tipo de obra relativamente frecuente a lo largo de aquel siglo, por lo cual, el autor se basa en algunas ediciones que circularon con relativo éxito, a pesar de sus evidentes limitaciones desde el punto de vista terapéutico. El manuscrito, que presentamos íntegramente, contribuye a ver la terapéutica del siglo XVIII desde una óptica diferente, alejada de los tratados de medicina o las farmacopeas oficiales que caracterizaban a la nueva ciencia ilustrada.

Palabras Clave: Recetarios médicos, Ilustración, Formularios de medicamentos.

\section{APORTACIÓN Á FARMACOTERAPIA DO SÉCULO XVIII: O RECEITARIO MÉDICO DE ANSELMO ARIAS TEIXEIRO}

Resumo

Entre unha serie de manuscritos do século XVIII atribuidos a Anselmo Arias Teixeiro localizamos o documento que amosamos nesta investigación, un conxunto heteroxéneo de receitas destiñadas a un público con escasos recursos económicos. Trátase dun tipo de obra relativamente frecuente ao longo daquel século, polo cal, o autor baséase nalgunhas edicións que circularon con relativo éxito, a pesares das súas evidentes limitacións dende o punto de vista terapéutico. O manuscrito, o cal amosamos íntegramente, contribúe a ve-la terapéutica do século XVIII dende unha óptica diferente, alonxada dos tratados de mediciña ou das farmacopeas oficiáis que caracterizaban a nova ciencia ilustrada.

Palabras Clave: Recetarios médicos, Ilustración, Formularios de medicamentos.

\section{CONTRIBUTIONS TO THE PHARMACOTHERAPY OF THE $18^{\mathrm{TH}}$ CENTURY: MEDICAL RECIPES BY ANSELMO ARIAS TEIXEIRO}

\section{AbStract}

Among a number of eighteen century manuscripts attributed to Anselmo Arias Teixeiro we had located the document presented in this research, a heterogeneous set of recipes aimed at a public with low income. It is a relatively common type of work throughout the century, whereby, its author based on some popular editions which circulate with relative success despite its limitations from a therapeutic point of view. The manuscript, which we present entirely helps to see the therapeutic of eighteenth century from a different perspective away from medical treatises or the official pharmacopoeia that characterize the new enlightened science.

KEY WORDS: Medical cookbooks, Medicinal forms, Therapeutic. 
Recibido/Received: 20/05/2015

Aceptado/Accepted: 06/07/2015

\section{EL AUTOR DEL MANUSCRITO}

lo largo de este artículo presentamos un documento inédito que forma
parte de un conjunto de manuscritos atribuidos a Anselmo Arias Teixeiro ${ }^{1}$,
miembro de una familia ${ }^{2}$ de la hidalguía rural orensana del siglo XVIII. Natural de la aldea de Cabanelas, en el actual ayuntamiento de O Carballiño, heredó el patrimonio familiar a la muerte de sus padres, contribuyendo así a la manutención del resto de hermanos, todos ellos dedicados a la vida eclesiástica. Una desahogada situación económica le permitió dedicarse, entre otras actividades, a la elaboración de vino, plasmando en un interesante manuscrito sus experiencias en este campo a lo largo de los años. Igualmente llevó a cabo escritos sobre otros campos histórico-científicos, describiendo experiencias y opiniones propias sobre cuestiones tan variadas como la luz, el fuego o, como el caso que nos ocupa, sobre terapéutica, siempre con cierto carácter autodidacta.

Podemos atribuir este manuscrito a Anselmo Arias Teixeiro porque al inicio del mismo intercala sus propios datos biográficos ${ }^{3}$, de la siguiente manera:

\footnotetext{
1 Vigo, Archivo Fundación Penzol, caja 100/24, Antonio Arias Teixeyro y Ulloa; apuntes de música, poesía, filosofía, etc, y recetas médicas. Este documento procede del archivo de la casa o pazo de Pías (Ramallosa, Pontevedra). A Pías, que fue durante años residencia de descendientes de los Arias Teixeiro, pudo llegar este manuscrito, a finales del siglo XVIII, desde Cabanelas y Vilar de Ordelles (Esgos-Ourense), donde residieron respectivamente Anselmo y su hermano Antonio, autor de otra serie de manuscritos, algunos ya publicados: Miguel Álvarez SoAJE, "Elaboración do viño do Ribeiro según un manuscrito do século XVIII”, Boletín das Ciencias, 21, núm. 66 (Nov. 2008). págs. 181-182.

2 Otros miembros destacados de esta familia fueron, Veremundo Arias Teixeiro (1741-1824), sobrino de Antonio e hijo de Anselmo, que fue Obispo de Pamplona antes de ser Arzobispo de Valencia en 1814 y Manuel Ramón Arias Teixeiro, Obispo de Santander. Más información se ofrece en: ConSEllo da Cultura Galega, "Anselmo Arias Teixeiro", en Album da Ciencia [en línea], disponible en $<$ http://culturagalega.gal/albumdaciencia/detalle.php?>, [consulta: 01/02/15].

3 Estos datos biográicos fueron verificados y desarrollados en el seno de nuestra tesis doctoral sobre ambos hermanos Teixeiro: Miguel Álvarez SoAje, Antonio y Anselmo Arias Teixeiro. Dos lulistas gallegos en el siglo de la Ilustración, tesis doctoral inédita, Santiago de Compostela, USC, 2012.
} 
Fui engendrado el año de mil 70 i 6, año de jubileo, a 2 de Marzo, mi padre caminando a 30 y mi madre a 10 i 84; mi padre con un barrunto de cólera y mi madre con resquicio de una calenturilla que a la mañana ya no había vestigios de ella, precedida de haberse llegado a demasiado fuego. Entre 8 y 9 de la noche y en lo seguro antes de la media noche fui engendrado. 8 días anduve de más en el vientre de mi madre. Nací a 10 de febrero, año de 1707, a las 4 de la tarde, caminando desde la media al tercero.

Efectivamente, estos datos corresponden con la fecha de nacimiento de Anselmo Arias Teixeiro quien, en algunos de sus escritos, deja ver un amplio conocimiento de otras obras científicas, lo que le permitió escribir sobre aquello que leía, intentando emular o trasladar a su entorno aquello que leía. El resultado de esta actividad es una serie de escritos variados entre los que se encuentra este recetario de medicamentos, un documento interesante en el campo de la sanidad popular a lo largo del siglo XVIII.

\section{EL MARCO CIENTÍFICO DEL SIGLO XVIII}

El marco científico español del siglo XVIII estaba caracterizado por un aristotelismo fuertemente enraizado en nuestras instituciones, ya que la revolución que comenzara en el siglo XVII se llevó a cabo de forma paulatina en nuestro país, principalmente en el ámbito privado y en contra de las universidades. En aquel ambiente observamos un incipiente racionalismo que, poco a poco, van defendiendo un grupo de científicos modernos, calificados en su momento como "novatores", cuyo celo en promover el avance científico no evitó que durante las primeras décadas del siglo XVIII todavía se defendieran postulados científicos de épocas pasadas intercalados con la filosofía natural, tal y como sucede con el manuscrito que aquí presentemos; un marco complejo que define la primera mitad del siglo XVIII en el que vivió el autor de nuestro manuscrito. A lo largo de ese período observamos un ambiente científico contradictorio, que permite la presencia de un destacado impulso innovador conviviendo con viejas tradiciones y supersticiones que se plasman en este caso en el uso de remedios terapéuticos

\footnotetext{
${ }^{4}$ Su padre, Pedro Arias Teixeiro, el Mozo, nació en 1676 y su madre, Petronila de la Peña, fue bautizada en Junio de 1689. Ambas fechas concuerdan con lo referido por el autor del manuscrito, Anselmo Arias Teixeiro, bautizado en la parroquia de Banga el 17 de Febrero de 1707, (Ourense, Archivo Diocesano, Libro parroquial 32.16.1, bautizados, casados y difuntos de Santa Eulalia de Banga, año de 1707).
} 
anacrónicos por parte de alguien que, al mismo tiempo, defendía la observación y la experiencia como herramientas fundamentales para el estudio científico.

A lo largo del siglo XVIII la experimentación fue una de las herramientas de que dispusieron los científicos para indagar en la Naturaleza y elaborar leyes y teorías, en la línea que ya en el siglo XVII defendía Robert Boyle al entender que las pruebas experimentales ofrecían mayor confianza que las propias matemáticas. De esta manera, el empirismo se impuso como fuente de información, desbancando al testimonio heredado de los antiguos.

Al igual que en el resto de Europa, el espíritu ilustrado español se caracterizó por su confianza en la razón humana como herramienta para superar viejos prejuicios y antiguos miedos, como el de pensar. Desde nuevos postulados se promovió el desarrollo científico y económico de la nación, apareciendo así obras científicas de gran interés como la Palestra Pharmaceutica de Félix Palacios, editada nueve veces a lo largo de la centuria, llegando a ser el principal tratado de química de la época. En 1726 Feijoo publicaba el primer volumen del Theatro Crítico Universal que iniciaba la divulgación generalizada de los conocimientos científicos y la lucha contra todo tipo de errores y prejuicios.

Por su parte, en Galicia, al igual que en el resto de España, constatamos la aparición de una generación de "ilustrados" en la segunda mitad de siglo, quienes, bajo la óptica de la filosofía natural intentaron aportar algo de luz en un entorno estancado en antiguas creencias y prejuicios, sin que la presencia de ciertos anacronismos deba entenderse como algo ajeno a la época en que nuestro autor redacta su recetario, tal como acabamos de exponer. Teixeiro responde a esa inquietud cultural de la sociedad de su época y, por ello, acomete la redacción de varios manuscritos y estudios científicos que nunca fueron editados, atado a viejas tradiciones e ideas que, a lo largo del siglo XVIII, mostraban ya su ocaso inminente. No obstante, responde al patrón de un sector de la sociedad gallega que mostraba inquietudes por poseer el conocimiento que secularmente se les había arrebatado en una tierra alejada de los círculos científicos del momento.

\section{CARACTERÍSTICAS DEL MANUSCRITO}

Se trata de un conjunto de cuartillas que conforman un recetario compuesto por cuarenta recetas que incluyen varios remedios basados en el uso de plantas (celedonio, naranja, tomillo, cantueso, salvia, romero, etc) y animales (buey, perros, lavanderas, gatos, etc). El documento lo forman ocho cuartillas escritas por ambas caras sin apenas márgenes, apaisadas, de unos 15 x $20 \mathrm{~cm}$, con una caligrafía poco clara sobre papel oscurecido. Las cuarenta recetas se incorporan en un texto que recuerda a los formularios de medicamentos, recetarios o cartillas 
farmacéuticas que circulaban impresos a lo largo del siglo XVIII ${ }^{5}$ y, ello, nos sitúa ante una obra relativamente frecuente en la época, no aislada, aunque manifiestamente temprana dentro de este conjunto de textos de utilidad sanitaria. Como ejemplo de esta dualidad entre el uso de remedios contemporáneos y anacrónicos Teixeiro recurre al uso de ciertas plantas que aparecían en las farmacopeas del momento, como salvia, romero, goma limón, cálamo aromático o el celedonio, a la vez que recomienda el cocimiento de lavanderas y perros, el uso del estiércol de gato, la grasa de culebras o el destilado de cangrejos. Por otro lado, recomienda con naturalidad el uso del beleño, la cicuta o la mandrágora para inducir el sueño en ciertos enfermos, especies vegetales que se encuentran entre los remedios habituales de muchas boticas de la época. En cuanto a sus "fuentes" oficiales, Teixeiro reconoce y hace referencia a varios autores de textos sanitarios, como Johann Schroeder, Pharmacopoea medico-chymica (Lyon, 1681), la Materia medica de Dioscórides (ejemplar comentado por Andres Laguna en 1566) o Jean Vigier, autor de una Historia de las plantas de Europa y de una Pharmacopeia Ulyssiponense), todas ellas, obras ampliamente referenciadas en las bibliotecas de muchas boticas, tanto seglares como monásticas.

Un aspecto llamativo del manuscrito es que, a lo largo del texto, numerosas palabras han sido ocultadas bajo un código que nos recuerda al empleado por los antiguos alquimistas para esconder ciertas ideas a miradas indiscretas. Así ocurre en este caso, en que Teixeiro, asigna a cada una de las cinco vocales un número del 1 al 5, es decir, $a=5, e=4, i=3, o=2, u=1$ con la intención de que la lectura del texto se haga más incómoda ${ }^{6}$.

\section{RELACIÓN DEL MANUSCRITO CON LOS RECETARIOS DE MEDICAMENTOS}

Los recetarios surgieron ya durante el siglo XVI como herramienta para la divulgación de remedios médicos de uso popular, obras de ámbito doméstico que recurrían a remedios caseros, de escasa justificación sanitaria pero baratos como una farmacopea sencilla. A lo largo del siglo XVIII se reeditaron varias obras de épocas anteriores, como el conocido Tesoro de Pobres o Thesaurus pauperum atribuido a Pedro Hispano, Petrus Hispanus (posible pseudónimo del Papa Juan XXI), obra de la cual se hicieron ocho ediciones entre los años 1705 y $1795^{7}$. $\mathrm{Su}$ contenido es una amalgama de remedios tradicionales con referencias a autores clásicos (Dioscórides, Llull o Avicena). A título de ejemplo, el texto refiere

\footnotetext{
5 Estos formularios están descritos en José María SuÑÉ Arbussa, Formularios de hospitales españoles. Siglos XVII y XVIII, Granada, Universidad de Granada, 2005.

6 Podríamos relacionar este hecho con algún tipo de vinculación alquimista del autor, pues en otros escritos incorpora referencias a obras alquimistas erróneamente atribuidas a Ramón Llull.
} 
como tratamiento para el dolor de sienes el uso de perejil, el cuerno de ciervo, la hierbabuena o el estiércol de paloma, todos ellos remedios de nula efectividad terapéutica. De igual modo, vemos que para reconfortar los ojos recurre a un remedio constituido por claras de huevo, leche de mujer que tenga hija, ojos de cierva, sangre de palomino y vidrio verde, todo molido y hecho un polvo que, una vez quemado, se echaría sobre los ojos. Es evidente que recurre a remedios caseros sin una justificación sanitaria, (no imaginamos el efecto del vidrio verde pulverizado sobre los ojos del paciente), con ausencia de fármacos elaborados o medicamentos de tradición farmacéutica. Como tercer y último ejemplo, el Thesaurus recomienda el uso de un lagarto verde vivo, cocido luego en aceite y que se colaría a continuación para hacer con él un ungüento, que se aplicaría eficazmente en la cara. Todos ellos, remedios muy similares a los propuestos por Teixeiro a lo largo de su manuscrito, en el que recomienda el uso de cocimiento de perros o la orina de buey, recordando que éste debe ser todo negro para que el remedio surja efecto.

La obra atribuida a Hispano responde a un estilo que se aproxima a nuestro manuscrito y es similar a otros títulos de la época, entre estes, el Florilegio medicinal de todas las enfermedades, sacado de varios y clásicos authores para bien de los pobres y los que tienen falta de médicos, de Juan de Esteynefer S.J., el Tesoro de medicinas para diversas enfermedades, de Gregorio López (1708), los Secretos médicos y chirurgicos del doctor Don Juan Curbo Semmedo (1735), la Medicina y cirugía racional y espagírica, de Juan de Vidós que, editada por primera vez en 1691, fue reeditada en 1709, 1720, 1722 y 1732, el Recetario medicinal espagírico de fr. Diego Bercebal ${ }^{8}$, la Medicina doméstica de Felipe Borbón (1686), reeditada en 1705, el Aviso al pueblo sobre su salud o tratado de las enfermedades más frecuentes de las gentes del campo, de Tissot o la Cartilla pharmaceutica chimico-galénica, de Pedro de Viñaburu, con una primera edición en 1729 y otra en la segunda mitad del siglo. Todo ello pone de manifiesto que el interés por este tipo de obras de pequeño tamaño y con carácter divulgativo tuvo gran demanda a lo largo de la primera mitad de la centuria, principalmente entre

\footnotetext{
7 Petrus Hispanus, Libro de Medicina, llamado Thesoro de Pobres, en que se hallarán remedios muy aprobados para la sanidad de diversas enfermedades, con un regimiento de sanidad. Compuesto por el Maestro Julián, que lo recopiló de diversos autores. Ahora nuevamente corregido y enmendado por Arnaldo Vilanova, Pamplona, Francisco Picart, 1727. Su primera edición en castellano data del año 1519. En el siglo XVIII fue editado los años 1705, 1722, 1727, 1734, 1764, 1765, 1791 y 1795; es decir, se editó de manera casi constante a lo largo de la centuria. Las ediciones de 1765 y 1795 iban acompañadas de una obra similar denominada Experiencias y remedios de pobres, de Antonio Bandinelli.

8 Antonio Claret García Martínez, "La enfermería franciscana en el siglo XVIII. Recetario medicinal espagírico (1713) de Diego Bercebal. Estudio y edición”, Hiades, revista de Historia de la Enfermería, 9 (2004), págs. 655-774.
} 
gentes con pocos recursos económicos y culturales, de ahí su amplia difusión en nuestro país.

La primera de las obras que hemos comentado, el Florilegio medicinal, representa por su título y su contenido el paradigma de este tipo de obras destinadas a gentes sin recursos, ofreciendo remedios elementales para todo tipo de enfermedades, por extrañas o incurables que pudieran parecer.

En el prólogo de los Secretos médicos y chirúrgicos, el autor (Juan Curbo) reconoce el éxito de sus 320 "secretos", tenidos por "golosinas" que han llevado al éxito su obra, pero no deja de ser uno más en el conjunto de obras aparecidas como remedio de todos los males de los pobres. Tal y como acabamos de comentar, estas obras iban dirigidas al pueblo llano, carente de recursos económicos para acudir a la medicina "oficial" y por ello alcanzaron gran popularidad a lo largo de todo el siglo XVIII. En ellas encontramos cualquier tipo de remedios que emplean toda suerte de ingredientes, que van desde el estiércol de paloma, a la pólvora, o del cuerno de carnero a las piedras bezoares, siempre precedidos de un supuesto y misterioso éxito en la consecución de sus objetivos. En no pocas ocasiones se recurre con poca lógica al uso de elementos químicos, como el oro o el mercurio; aunque ambos quedaban fuera del alcance del pueblo el resto de remedios ofrecidos se podían hallar en cualquier vivienda de la época, como azafrán, manzanilla, huevos, vino, lombrices, gusanos, hollín de chimenea, orinas de buey, leche, miel, etc. En algunas obras publicadas hasta bien entrado el siglo XIX aun se venía recurriendo al uso de este tipo de remedios caseros.

Otro tipo de texto divulgativo lo representan las denominadas Cartillas farmacéuticas, obras que iban destinadas a fomentar la formación e instrucción de los aprendices de boticarios. Solían ser obras de pequeño tamaño, como la de Viñaburu (1729) ${ }^{9}$, escritas en forma escolástica a base de una serie de preguntas y respuestas para facilitar la memorización del contenido por parte del alumno. Algunas, como la de Montañana continuaba ofreciendo referencias a la obra de Dioscórides como modelo para el estudio de la botánica, mientras que Viñaburu reconoce en su obra la influencia de Mesué. Sorprende en la Cartilla de éste último el predominio casi exclusivo de remedios de origen vegetal, pero ello, junto a la propia estructura del texto, enfocado a una actividad memorística, posicionan al autor en la tradición médica de siglos anteriores. La Cartilla, como señalan Peralta-Reglado y Gomis (2006), a pesar de estar proyectada como obra docente divulgativa, acabó convirtiéndose en libro de texto para superar el examen de boticario. Posteriormente apareció la cartilla de Ambrosio de Almunia, Porras ilustrado y cartilla de examen para cirujanos latinos y romancistas (1732), des-

\footnotetext{
9 Pedro Viñaburu, Cartilla pharmaceutica chymico-galénica, Pamplona, Joseph Joachin Martínez, 1729.
} 
tinada principalmente a cirujanos pero con una estructura y composición similar a las anteriores. En 1761 el boticario madrileño Francisco Brihuega publicaba otra obra de similares características pero de contenido más actualizado, el Examen Pharmaceutico Galenico Chimico, destinada a los boticarios que pretendían superar el examen del Protomedicato; una obra que, sin embargo, no aportó nada novedoso a la farmacopea de la época.

Otra obra destinada a la sanidad de los más pobres y aparecida a principios del siglo XVIII, fue el Libro de Medicina y remedios de las enfermedades por orden alfabético. Sacado a la luz de diferentes autores y en particular del B. Gregorio López. Por el Ldo D. Pedro de Biureta, residente actual en la villa de Madrid. Madrid, Juan García Infanzón, 1703. Su contenido es similar al manuscrito de Teixeiro y en la línea de las publicaciones que hemos comentado y, por ello, en el título, el autor señala que los remedios ofrecidos en el texto fueron tomados de otros "autores", sin especificar quienes, de tal forma que el conjunto de remedios, de escasa efectividad, se debería a terceras personas que los habrían probado con gran eficacia desde la antigüedad. En esta ocasión, Biureta lo dejó bien claro en la introducción de la obra, al afirmar que "fue motivado por la humana condición de comunicar a sus próximos los remedios que el talento humano ha descubierto por imitación de la Naturaleza". La obra lleva la aprobación del médico primario del Rey, así como del doctor Diego Matheo Zapata, que reconocía el interés de la misma para pobres y aquellos pueblos donde no hubiera médico, reconociendo además, la utilidad y seguridad de los medicamentos propuestos, basados en la experiencia.

No debemos olvidar, por último, el elenco de obras de exaltación de panaceas, obras editadas a lo largo del siglo XVIII, destacando entre ellas los polvos purgantes del médico francés Jean Ailhaud (1674-1756) o el recetario francés de Marie Maupeou de Fouquet, Obras medico-chirurgicas de madama Fouquet, editada en Valladolid (1748) y Salamanca (1750).

Podemos situar el manuscrito de Teixeiro hacia los años cuarenta o cincuenta del siglo XVIII, ya que éste falleció en 1756 después de una larga enfermedad. Por tanto, se sitúa a la vez que los primeros formularios de medicamentos que, con cierto rigor científico, ya circulaban en los años cincuenta de aquella centuria, algunos militares y otros civiles, normalmente pertenecientes a boticarios de hospitales y personal cualificado, al contrario que las obras de divulgación popular ya comentadas. El primero de ellos, Sinopsis Formularium, fue editado en 1741, reeditándose en 1742 y 1749, lo cual apunta su amplia distribución. En 1752 se publicó el Formulario médico-chyrurgico del que se tiraron 900 ejemplares y que incluía hasta 120 recetas en latín. Siete años más tarde, en 1759, Felix Eguia publicó su Formulario de medicamentos y en 1760 se editó la Farmacopea de la Armada, obra del boticario Leandro de Vega que, a pesar de su denominación, 
parece ser, más bien, un formulario para uso de médicos y boticarios de la Armada española. Poco después, en 1763, se publicaba el Formulario del Hospital del Cardenal de Sevilla, obra escrita por Carlos Serra Rossell e, incluso a finales de siglo siguieron apareciendo formularios de medicamentos como los Formularios de Cartagena de los Hospitales de la Armada, editado en 1789 y 1795 y el Formulario de los Reales Hospitales General y de la Pasión de Madrid, del año 1789, que incluían como remedios terapéuticos sustancias animales, metálicas, vegetales, zumos, raíces, electuarios, jarabes, etc.

Nuestro texto incorpora, también, un amplio abanico de remedios animales y vegetales, tal como hemos apuntado ya. Contabilizamos en él dos colirios, cuatro bebidas, cinco emplastos, varios enjuagues, cinco jarabes, tres zumos, un electuario, tres soluciones, dos ungüentos y varios aceites, infusiones, destilados y remedios animales. Por otro lado, encontramos recetas difícilmente encuadrables bajo forma farmacéutica alguna, como la que recomienda ponerse unos escarpines humedecidos en aguardiente y dormir con ellos una noche para tratar la ronquera de pecho. Sin embargo, en otro momento Teixeiro recomienda practicar ejercicio y abstenerse de la carne de cerdo, sustituyéndola por caldo de gallina.

El texto, por tanto, se enmarca en un período en el que es frecuente la publicación de recetarios, alguno de los cuales podría haber llegado a conocer Teixeiro y, basándose en ellos, elaboró el suyo propio. Pocas obras de interés exclusivamente terapéutico podría haber manejado de entre las publicadas hasta aquellas fechas y que hubieran tenido amplia difusión; entre ellas podemos citar, en primer lugar, la obra de José Pasqual Llobet, Particulares medicamentorum, (1677) publicada como formulario del Hospital de Santa Cruz de Barcelona. En segundo lugar, destacamos la conocida obra de Dioscórides, Acerca de la Materia Médica Medicinal y de los Venenos Mortíferos, ya que es en ella donde encontramos las fuentes que sirven de base científica a Teixeiro, una obra obsoleta a mediados del siglo XVIII pero que aun gozaba de gran reputación entre médicos y boticarios, no obstante apareció una última edición a principios de aquella centuria.

Varias recetas del manuscrito de Teixeiro tienen sus correspondientes en la obra de Dioscórides, siendo evidente que el ejemplar manejado para redactar su recetario fue la edición española comentada por Andrés Laguna, (edición de 1555).

En general, estas obras estaban dirigidas a profanos, consideradas como obras de higiene privada dedicadas a ofrecer remedios para todo tipo de enfermedades pero que apenas aportaron novedades terapéuticas y cuyo contenido, además, era distinto entre unas y otras; unas obras que, por otro lado, no valoraban el origen de la enfermedad ni cómo evitarla, ofreciendo a las clases más pobres unos remedios secretos basados en la tradición oral popular. 
No resulta extraño recurrir a una terapéutica tan antigua en pleno siglo XVIII, porque no estamos ante un caso particular de retraso cultural o científico, sino en un ejemplo de terapéutica popular habitual entre las gentes con pocos recursos económicos, como venimos comentando; era, en definitiva, una terapéutica válida y ajustada a su época, pues poco más era lo que se conocía. Pero, por otra parte, tampoco nuestro autor se propuso editar un formulario nacional para uso generalizado, sino una pequeña guía de remedios caseros. No debemos considerar a Teixeiro como persona ajena al ámbito sanitario, pues hasta bien entrado el siglo en este campo encontramos desde médicos y boticarios hasta santos, curanderos y brujos; en ocasiones, la ignorancia de unos y otros era similar. Además, la situación de la medicina y la farmacopea oficiales en la España del XVIII era lamentable, como denunciaban ya Feijoo, Sarmiento o el médico José Masdevall ${ }^{10}$. A lo largo del recetario de Teixeiro encontramos remedios para todo tipo de males, algunos con ciertas reminiscencias alquimistas. Así podemos ver una receta para el tratamiento de la fluxión (catarro o resfriado) que, desde la cabeza irradia al resto del cuerpo; su origen, según Teixeiro, no es la alteración de la circulación de los humores en las venas, sino el tiempo atmosférico cuando pasa de seco a húmedo inmediatamente y de caliente a frío, lo cual conlleva que se "coagulen los líquidos". A su entender, la humedad del aire penetra por los oídos, narices y boca y contacta con algún órgano en el cerebro, lo que provoca que la linfa comience a circular desencadenando la enfermedad, que debe tratarse, no con medicamentos, sino tratando las partes aéreas de la cabeza. Para ello recurre a un remedio que mezcla lo casero con lo alquímico, tapando los oídos con algodón empapado en vino blanco y colocando un paño fino delante del rostro, de tal forma que oculte la nariz y la boca para evitar la entrada de aire. Este paño iría empapado en "vino filosófico", no en un vino corriente. En diferentes tratados de alquimia, como el Theatrum chemicum (1602), existen referencias al denominado "vino filosófico", un tónico y digestivo elaborado a partir de un vino "digerido" durante un mes en estiércol de caballo y destilado posteriormente. Los remedios así preparados debían tener un efecto mayor que con el alcohol etílico ordinario.

Es interesante destacar, también, el interés de nuestro autor en recurrir a la observación y la experimentación. A lo largo del manuscrito encontramos referencias a "como me lo enseña la observancia y la experiencia". Entendemos, por tanto, que la justificación de sus remedios viene dada, en unas ocasiones, como resultado de su propia experiencia y, en otras, fruto de la tradición oral, no demostrada por sí mismo.

\footnotetext{
${ }^{10}$ José MaSdeVall (1725?-1801), médico español, autor de una Relación de las calenturas pútridas y malignas, Madrid, Imprenta Real, 1786.
} 
En este sentido, Teixeiro señala, por ejemplo, que la putrefacción de un cuerpo se debe a la fijación de la humedad extrínseca o intrínseca en sus cavidades. El poso o sosiego de los líquidos estancados sería el origen de esa putrefacción pero también influye el calor, aunque refiere lo dicho por Boyle respecto a los peces que mueren bajo los hielos al congelarse el mar Báltico. Algo parecido pudo comprobar en el agua de una fuente que, inmovilizada durante cuatro meses, se pudrió, lo cual observó también en las aguas termales, "que se enfrían en contacto con el aire" y, durante el verano, en los seres humanos cuando enferman al pasar del calor al frío, desencadenando "catarros y fiebres". Señala Teixeiro que a la putrefacción sigue la destrucción del cuerpo putrefacto, lo que da lugar a que se engendren gusanos; esta afirmación nos aproxima a la teoría de la generación espontánea de gusanos o Autogénesis, una teoría que a lo largo del siglo XVIII era reconocida y entendida como posible por varios autores, aunque desde 1769 fue refutada por Spallanzani y Francesco Redi tras llevar a cabo una serie de experimentos para demostrar o invalidar la aquella teoría. En relación a estas teorías, por entonces se suponía la generación humana surgida de un huevo que se pudriría en la vagina de la mujer; en este sentido, Teixeiro apunta la idea de que el semen del hombre no haría más que fomentar esa putrefacción de la misma manera que el agua de lluvia "pudre" el interior de la tierra para generar las plantas; por otro lado, nos dice que el agua del interior de la tierra se puede pudrir para desarrollar los metales y, por ello, entiende que todas las tierras mineras son tierras esponjosas y húmedas, afirmando que el "hedor sulfúreo" que percibe en los minerales se debe a esa naturaleza putrefacta. Acompaña sus argumentaciones con ejemplos, unos entresacados de los escritos de Boyle acerca de la metalurgia y otros observados en su entorno, como lo sucedido en "la cueva de Villa", en la que observa aguas sulfúreas.

Otro tipo de putrefacción parece encontrarlo en cierto "vello" que observa en algunas hojas y hierbas, entendiendo que se forma debido a la humedad del entorno ${ }^{11}$, de manera similar a lo que ocurrió en su momento en "la caja de las pelucas, que contenía tierra". Por otro lado, asegura que como todo ser vivo depende de la humedad, y como, además, el agua de cada ser vivo no vuelve a la naturaleza y el agua en la naturaleza es limitada, con el paso de los siglos ésta se irá consumiendo y llegará un momento en que, por falta de agua en los mares, cesará la lluvia y, por tanto, "toda generación de materia". Entiende que, por ello, se observa menos nivel de agua que en siglos anteriores y más cantidad de tierra,

\footnotetext{
${ }^{11}$ Entendemos que hace referencia a ciertos mohos que observa en las hojas que han estado en contacto con el agua, que también pueden aparecer en una caja de cartón cerrada, debido a la humedad procedente de la tierra contenida.
} 
a su modo de ver, transmutada originalmente del agua ${ }^{12}$. Por último y a modo de conclusión del manuscrito pone en duda la veracidad de las tablas de Ptolomeo.

\section{TRANSCRIPCIÓN E INTERPRETACIÓN DEL MANUSCRITO}

Veamos el contenido del manuscrito, que carece de introducción, aunque como hemos apuntado ya, en el texto se intercalan sus datos biográficos:

$\mathrm{R}^{13}$ : Aguamiel, buena para la gota, bebida pero ha de ser cocida; aprovecha en gran medida a los asmáticos y tosigosos ${ }^{14}$ y no se debe dar a coléricos inflamados de algún miembro; para ablandar el vientre se da cruda y sin cocer. Para provocar vómito se mezcla con un poquito de aceite tibio. Prepárese esta agua así: tomaréis de agua de lluvia lib. Vy de miel de abejas, lib. II y cueza a fuego manso hasta que mengüe el tercio, procurando siempre irla espumando y se ponga en vasija vidriada. Para el pecho se le añade fenugreco ${ }^{15}$ y un poquito de salvado. Es eficacísima para la vista turbulenta, nitilopatias ${ }^{16}$, cataratas, lavando los ojos con ella y, tomada por las narices, descarga mucho el cerebro. Rica para apostemas intrínsecas y para evacuar humores gruesos ${ }^{17}$.

\footnotetext{
${ }^{12}$ Desconocemos en qué se basa Teixeiro para manifestar que el nivel de agua era entonces inferior al nivel de siglos anteriores.

${ }^{13}$ Señalamos cada receta con la letra $\mathrm{R}$ para que resulten más fácilmente identificables, pero no aparecen así en el original manuscrito.

${ }^{14}$ Tosigosos, entiéndase envenenados, emponzoñados o que padecen tos. El Aguamiel se prepara por fermentación de una mezcla de agua y miel, de la que se obtiene una bebida alcohólica. Se suele emplear una proporción de $25 \mathrm{~kg}$ de miel por 83 litro de agua para hacer una correcta mezcla, fermentable. En ocasiones se le añade polen de abejas o levaduras vínicas procedentes de uva moscatel para asegurar la fermentación de la mezcla. En el manuscrito de Teixeiro se recomienda la Aguamiel sin fermentar pero sí cocida. Sin cocerla, la aplica sobre el vientre y para promover el vómito la da mezclada con aceite, preparándola con agua de lluvia y miel, espumándola continuamente durante el hervido. Dioscórides y Teixeiro coinciden en los usos y formas de administración de este remedio lo que nos lleva a suponer que el de Cabanelas tuvo al primero como fuente de información para éste y otros remedios. Ambos coinciden en su utilidad para la gota y en su preparación, aunque Teixeiro ofrece su particular opinión al respecto.

${ }^{15}$ Fenogreco, también denominado Trigonella foenum-graecum o Alhova, planta herbácea utilizada hoy en día como estimulante del apetito. Es una variedad de legumbre, de sabor amargo que contiene un aceite esencial que estimula las glándulas digestivas. Se le atribuyen ciertas propiedades anabolizantes, a la vez que reduce considerablemente los niveles de hiperglucemia, por mejorar la respuesta pancreática.

${ }^{16}$ Nitilopatías, entendemos que es un término que hace referencia a alguna patología ocular, quizá glaucoma.

${ }_{17}$ Esto es lo que indica la obra de Dioscórides, Acerca de la materia medicinal y de los venenos mortíreros, Salamanca, Mathias Gast, 1566, pág.512: ... usamos del aguamiel en aquellos que siendo hombres de edad viven enfermos de gota. Siempre se debe administrar cocida. Administrámosla cruda cuando queremos molificar el vientre o provocar algún vómito, como aquellos que bebieron
} 
Libro de Mágica blanca ${ }^{18}$, hailo en Monfero de Galicia, monasterio de bernardos y de dominicos en Salamanca.

R: Para los tullidos por accidente u otro cualquier encogimiento de miembros, después de evacuada la naturaleza no hay tal, como muerto un buey en la cuadra donde asiesten y éste que esté bien grueso y abriéndolo cuanto más pronto, se pudiere entrar al doliente dentro muy bien tapado y de suerte que solo la cabeza quede fuera; remedio moderno y eficacísimo.

Conocimiento de los que han tomado unciones: frente con unas pocas de arrugas, con algunas caspas negras o blancas, color pálido, labios arrugados y quemados, pestañas y cejas poco pobladas.

R: Remedio para la cólica; cocer una naranja agria y beber el agua, al otro día purgarse y si puede, de agua beber cuartillo y $m^{\circ}$. De vino, para alegrar con uno cualquier cosa, por la mañana es mejor, pues si es colérico, a la tarde está más y a la mañana menos. Ha de procurar siempre beber aguas delgadas o cocidas con zarza ${ }^{19}$.

$\mathrm{R}$ : Risa sardónic ${ }^{20}$ porque hay una hierba venenosa que, comida, hace abrir la boca a modo de risa y mata color sardónico, lo mismo que vergüenza, por la

venen, a los cuales se la solemos dar con aceite. Dámosla cocida a los tossigosos, a los que tienen apostemado el pulmón(...). Prepáranla mezclando con dos partes de agua llovediza muy reposada, una de buena miel(...) y cuézanla hasta que se gaste la tercia parte.

${ }^{18}$ Recuérdese que lo escrito entre paréntesis y subrayado se encuentra oculto en el original, (Mágica blanca $=$ M5g3c5 b15nc5). Existe una obra publicada en Madrid, en 1755, por Pablo Minguet e Yrol sobre la magia blanca, bajo el título de Engaños a ojos vistas y diversión de trabajos mundanos fundada en lícitos juegos de manos (...) pero Anselmo no la pudo encontrar en el monasterio de Monfero, cenobio cisterciense situado en la provincia de A Coruña. Otras obras dedicadas a la magia blanca podrían ser la de Reginal Scott (1538-1599), Discovery the witchcraft, publicada en 1584, o la de Hernando Castillo S.J., Historia y Magia Natural o ciencia de filosofía oculta (...) con nuevas noticias de los más profundos misterios y secretos del Universo visible, Madrid, 1692, obra que sí podría haberse hallado en Monfero.

19 Para la Cólica, que Pedro Biureta en Libro de Medicina y remedio de enfermedades, Madrid, Juan García Infanzón, 1703, define como una pasión del intestino colon, con dificultad de obrar y propone como tratamiento un remedio distinto al de Teixeiro pero similar en cuanto a su naturaleza, en la línea de ésta y de otras obras de medicina destinadas a los pobres. Propone Biureta las hojas de sauce mojadas y bebidas con vino, pero también la pimienta con aceite en que haya hervido ruda, bebido todo en caliente, azufre sorbido en un huevo, estiércol de cabra deshecho con aceite y agua, puesto tibio sobre la zona dolorida, estiércol de perro, alcaravea y simiente de ruda con vino, manteca de vacas, orina de niños y pezuña de las manos del "puerco", pulverizado y bebido con vino. Por su parte, Juan Curbo Semmedo en Secretos médicos y chirurgicos, Madrid, Juan de Zúñiga, 1735, propone para la cólica o dolor cólico, tomar aceite de manzanilla y de manteca de azar, hervir y hacer una torta de estopa para colocar en el vientre. La estopa se empapará con huevos revueltos y todo ello se llevará a una sartén para que cuaje, antes de su aplicación en la zona a tratar. 
abundancia de tinte de grana que hay en esta ciudad. Sardanapalo, hombre el más lascivo y más afeminado que hubo. "Esteocles y Apolinicies", dos hermanos que se quisieron tan mal que aún estándolos quemando en la hoguera la llama del uno se apartaba de la del otro ${ }^{22}$. Ibis, ave sucia que saca con el pico el excremento del orificio.

R: Para los ojos tómese celidonio ${ }^{23}$ y un poco de vino, puestos los canutos en él, exprimiendo 4 onzas o machacándola en él se da con el vino en los ojos y se sacan las nieblas o bellidos, que llamamos.

R: Para sacar el sol de la cabeza: una redoma llena de vinagre o agua puesta en la cabeza.

R: Virtudes del te para dolor de cabeza, de estómago, para la borrachera, tomando cocido en agua y beber el agua; para la borrachera, aplicar nieve o agua a las tomas.

R: Para la piedra, una lavandeira, que llamamos, echada viva en una olla nueva hasta que la dicha ave con plumas y todo se vuelva polvos. Dejar estar la olla al fuego y después que en la misma olla se vuelva todo polvos se usa de ellos en un poco de agua en ayunas. Para aliviar y quitarle por entonces a uno que actualmente está con dolor de piedra, no hay tal, como unos pocos de ajos cocidos en vino blanco aplicados al empeine o riñones. Pero el mejor y más excelente para hacer echar las pedrezuelas, flemas y las materias hediondas de los riñones y vejiga es el siguiente: tomaréis doce limones hechos rodajas, los echaréis en seis escudillas de agua dulce, que no sea de pozo ni mar y ésta se cueza hasta que mengüe la tercia parte y, colado, le añadiréis ocho onzas de aceite común, y de azúcar blanco media libra y, al fuego, sea hecho jarabe y tómelo en ayunas, cuatro onzas con agua de grana.

\footnotetext{
${ }^{20}$ Hace referencia a la convulsión o contracción de los músculos de la cara de que resulta un gesto similar a cuando una persona se ríe, provocada por la hierba sardonia, Ranunculus sceleratus, cuyo jugo inflama el aparato digestivo y provoca la contracción de los músculos de la cara. DioscóRIDES, op. cit. pág. 251: Al ranúnculo le llaman apio silvestre o Apium risus, que es apio que constriñe a reir, porque los que lo comen se mueren riendo a regañadientes (...) también se llama Sardonia.

${ }^{21}$ Sardan afeminado o Sardanapalo, fue un rey legendario de Nínive, en Asiria, poco belicoso por lo que en este caso el término alude a aquella persona de carácter afeminado y disoluto.

${ }^{22}$ Eteocles y Polinices; ambos hermanos, conocedores de los crímenes cometidos por Edipo, su padre, se negaron a socorrerlo cuando fue desterrado y convinieron reinar cada uno un año en Tebas pero, tras el primer año, Eteocles no quiso ceder el trono y eso les llevó al enfrentamiento en el cual murieron ambos hermanos.

${ }^{23}$ Celidonia mayor o Chelidonium majus, es una papaverácea de la cual no hemos encontrado una posible utilidad real para la vista; además, el autor indica tómese Celedonio, lo cual provocaría efectos sedantes y antitusivos bajo el riesgo de una elevada toxicidad para el paciente. Es una planta herbácea con propiedades antiespasmódicas, hipnóticas y analgésicas. Sobre la Celidonia indica DioscórIDES, op. cit. pág. 152: ...mostrónos la golondrina el uso de la Celidonia contra la ceguedad. Más adelante, en pág. 256: ...su zumo cocido con miel en un vaso de cobre es útil para clarificar la vista.
} 
También este jarabe es admirable para las purgaciones prevenidas de mujer que sea cálida, y esto se conoce en el color porque si es muy blanca es fría, como también si es muy morena, pero si es trigueña es caliente y entonces se usa de este jarabe. Pero si es fría se le añade al dicho jarabe un poco de trementina, y sanará luego. También es rica el agua que se saca de las sandias; esto es, sacada la corteza se exprimen y aquella agua que rezuman es rica para las purgaciones precedidas de causa cálida.

R: Para Cólica, que es cuando duele mucho el vientre y no se puede orinar, es eficacísimo el siguiente: tomad un poco de estiércol de gato o ratones y poned una taza de vino a la lumbre y, echados los polvos de dicho estiércol en el agua, bebedla y sanaréis luego.

R: Para llagas de bala, cuchillas y otras cualesquiere, tan eficaz que atrae y saca cualquier hierro que quedare dentro y después encarna y cura la llaga perfectamente, es el siguiente: tomaréis dos perrillos recién nacidos, vivos, lombrices de tierra, lib.j ${ }^{24}$, aceite de lirios, libra ij ${ }^{25}$, trementina de Venecia un $g$ $v i^{26}$, agua caliente, un $\mathrm{gj}^{27}$. El cómo se ha de hacer: pondréis al fuego el aceite con los dos perros vivos en olla vidriada y cuezan alli hasta que la carne aparte de los huesos y luego echaréis las lombrices lavadas con vino blanco ${ }^{28}$ y hierva todo junto, otra vez, hasta que estén tostadas las lombrices y con paño tupido se cuele fuertemente y luego añadiréis la trementina y el aguardiente y guárdese en vaso de vidrio. Úsese de él cuando se ofrezca, que es excelentísimo.

$\mathrm{R}$ : Los granos que quedan en el rostro cuando se dispara algún arma de fuego, los dichos granos de pólvora fijos en el rostro o manos sacaréis en el primer aparato, lavándolos con la poscajaia, que es agua y vinagre ${ }^{29}$; con esto se deshacen.

\footnotetext{
${ }^{24}$ Medidas de peso empleadas hasta el siglo XIX Lib.j $=1$ Libra

252 Libras

${ }^{26} g v i=6$ granos, de trementina de Venecia; se trata de un líquido obtenido por destilación en vapor de la resina de varias especies de coníferas. La de Venecia es más odorífera y transparente que el resto, siendo extraída del alerce, tradicionalmente en el área de Venecia. En 1545, Ambroise PARÉ publicó una obra sobre el tratamiento de las heridas por bala de arcabuz, Méthode de traiter les plaies faites par les arquebuts et autres bastons a feu, París, 1545, (Método de tratar las heridas causadas por arcabuces y otras armas de fuego). Propone Paré el tratamiento de estas heridas con yema de huevo, aceite rosado y trementina. BIURETA en Libro de Medicina ... propone como tratamiento de las llagas yema de huevos cocidos, trementina, resina, almáciga, incienso y mirra, mezclando todo y aplicándolo sobre las heridas.

${ }^{27} g j=1$ grano

${ }^{28}$ Las lombrices lavadas con vino blanco utilizadas en tratamiento de heridas de bala es un remedio que refiere también fray Miguel Agustín para el tratamiento de la Amarillez, en Libro de los secretos de agricultura, casa de campo y pastoril, Barcelona, 1722.

${ }^{29}$ El uso de vinagre lo entendemos por su actividad desinfectante; el agua ayudaría a limpiar las heridas. No hemos encontrado referencias al término poscajaia, aunque la Posca era una bebida popular habitual en la antigua Roma, compuesta por agua y vinagre u obtenida de vinos de baja calidad avinagrados.
} 
R: Para las quemaduras de pólvora de agua o de aceite u otra cualquier cosa, es éste: luego que sucede la quemadura tomaréis cebollas y majándolas les sacaréis el zumo, en el cual echaréis una poquita de sal molida y con esto unte con una pluma de gallina la quemadura y le aplique parches mojados encima. Aceite de Ambrosio ${ }^{30}$, para las llagas aunque estén hundidas y tengan estrecho el orificio, dilatarlas es este recipe: resina de abeto ${ }^{31}$, un $c v^{32}$, aceite tostado, un $g I^{33}$ y media, hypericum, drag $V^{34}$, simiente de momordica ${ }^{35}$, llamada poma de amor $^{36}$, drag III ${ }^{37}$. Muélase un poco la simiente en vaso doble con el aceite y trementina. Se ponga a hervir, espacio de media hora y luego se cuele y ponga en vaso de vidrio, del cual se ponen pañitos mojados encima de la herida.

R: Para atajar un flujo de sangre en menos de media hora no hay tal como garjear las heridas con un poco de agua ardiente fría y para la llaga curarla, el ungüento de bolo ${ }^{38}$, paños mojados en zumo de llantén ${ }^{39}$, aceite rosado y unas gotas de vinagre, remedio eficaz para sanar el dolor de alguna parte que duele por causa de fluxión o para el reumatismo, a su principio o ataque de ciática:

${ }^{30}$ El cirujano Ambrosio Paré, (1510-1590), empleaba aceite de saúco hirviendo para cauterizar las heridas de bala, ya que en las obras de Galeno que entonces se manejaban, no se reflejaba este tipo de herida.

${ }^{31}$ Dioscórides, op. cit. pág. 54: ... (el abeto) tiene la virtud de soldar las heridas frescas.

${ }^{32} c v=5$ granos

${ }^{33} \mathrm{~g} \mathrm{II}=2$ granos

${ }^{34}$ drag $\mathrm{V}=5$ dracmas de hipérico (Hypericum perforatum), planta empleada actualmente como antidepresivo.

${ }^{35}$ Momordica: Momordica charantia, planta de la familia Cucurbitáceas, también llamada Cundiamor y Melón Amargo. Extendida por todo el mundo, Africa, China, India, Brasil etc, se usó para mordeduras de insectos, problemas menstruales y de estómago. Su fruto, parecido al pepino, verde, es una fuente importante de vitamina $\mathrm{C}, \mathrm{A}$, fósforo y hierro.

${ }^{36}$ Dioscórides, op. cit. pág. 424, la denomina poma amoris.

${ }^{37}$ drag III $=3$ dracmas

${ }^{38}$ En la obra de Diego BerCEBAL, Recetario medicinal espagírico, Zaragoza, 1735, encontramos también una referencia a este remedio para tratamiento del carbunco, practicando un orificio en un paño y colocando en él la pústula. Aplicando a continuación el ungüento de bolo y luego un cáustico hecho de solimán y pimienta blanca. La operación debería repetirse varias veces. A lo largo de esta obra de Bercebal encontramos remedios muy similares a los descritos por Teixeiro pero ninguno exactamente igual. Bercebal recurre al empleo de solimán, a lavados con vino blanco, muchos remedios a base de plantas, rasuras de diente de jabalí, huevos cocidos e incluso refiere el uso del oro (oro de Adriano) en algunas de sus recetas. En la relación de medicamentos existentes en la botica de Castejón de Sobrarbe, Jesús CARDIEL, La botica de Castejón de Sobrarbe en el siglo XVIII. Revista el Gurrión, 103 (2006) encontramos referencias al Ungüento de bolo junto a otros ungüentos, como el de Basilicón, de calabaza o de diapalma, pero el autor no hace referencia a su exacta composición. ${ }^{39}$ Llantén, Plantago major, planta herbácea empleada hoy en día como antitusivo. De él trata DiosCórides, op. cit. pág. 209: No hay cosa que tan valerosamente restañe toda efusión de sangre, mezclado su zumo con claras de huevo y bolo armenio en paños sobre la frente y sienes, o dentro de las narices. 
recipe orinas podridas y cuando estén bien pasadas y añejas, vino blanco y aceite, iguales partes, póngase a la lumbre, hiervan bien y darle a la parte con esto.

R: Para la lepra, después de evacuada la causa con caldos de culebras y purgas y aún las unciones secretas de lo gálico, una onza de solimán ${ }^{40}$, mercurio sublimado ${ }^{41}$ desatada en una libra de cal viva y úntese el cuerpo. La grasa de culebras, buena para ciática.

R: Para sacar las señales de llagas y otras cualesquier infecciones o manchas del rostro, recipe: mirrha, un gII', muélase bien y tomaréis media docena de huevos cocidos que estén duros y mondados. Los cortaréis a la larga por medio y sacadas las yemas, se llenan las cavidades de mirrha. Pónganse en lugar húmedo en una "almofia", y tapados muy bien, de modo que no caiga en ellos polvo ni cosa alguna; estén cuatro días metidos en un "ojo" en alguna bodega hasta que la mirrha y las claras se deshagan en un aceite graso; guardarlo para lo dicho ${ }^{43}$.

\footnotetext{
${ }^{40}$ Solimán, también llamado Azogue, es el mercurio. Dioscórides, op. cit. pág. 542: ...el solimán aplicado al rostro extirpa las señales y manchas.

${ }^{41}$ Mercurio sublimado, también denominado Sublimado corrosivo ya que es una sustancia quemante, acre y corrosiva que al ser aplicada al cuerpo humano ejerce una actividad cáustica. Se aplicaba en uso externo para abrir ciertos tumores y consumir los bordes o márgenes de las úlceras. Se "dulcificaba" el sublimado con agua de cal para conseguir su descomposición. Fue muy representado en la bibliografía de la época hasta bien entrado el siglo XIX. Tradicionalmente el mercurio fue obtenido en las minas de Almadén y Almagro a partir del Cinabrio, que se molía para su fusión, recibiendo entonces el nombre de Bermellón, sustancia adecuada para la fabricación de pinturas. Por otro lado, el azogue o mercurio, metal líquido obtenido por la fusión del mineral, era la base para la elaboración del Solimán mediante un proceso de sublimación de mercurio y "salitre", resultado del cual es un producto corrosivo que, como hemos apuntado ya, fue muy recurrido en la medicina de la época como cauterizador. La preparación del Mercurio sublimado podía hacerse, según refiere Félix PALACIOS, en Palestra pharmaceutica chymico-galénica, Madrid, Joaquín Ibarra, 1763, colocando en mortero de piedra mercurio vivo con sal común decrepitada junto con Salitre, el Vitriolo calcinado y el Caput mortuum del vitriolo. Humedeciendo la masa con aguafuerte se mezclaba todo y se colocaba en una cucúrbita de barro que se ponía a continuación en un horno para calentar hasta que no ascendiesen vapores. En ese momento se separaba el solimán y se guardaba para su uso.

${ }^{42} \mathrm{gII}=2$ granos

${ }^{43}$ Dioscórides, op. cit. pág. 48: Hácese un excelentísimo aceite de myrra para cosortar los murecillos y nervios y restituirles su movimiento perdido en esta manera.Toman una docena de huevos cocidos con su cáscara, duros y después de mondados, los parten a la luenga por medio y les sacan las yemas. Hecho esto, hinchan aquellas concavidades de myrra perfecta y muy bien molida y dejan asi los dichos huevos estar en una bodega puestos entre dos platos por término de 3 o 4 días, hasta que la myrra con las mesmas claras cocidas se venga justamente en deshacer a un óleo oscuro de la espesura de arropel, el cual se guarda para muchos efectos (...) porque hincha las llagas hondas y quita las señales del rostro por antiguas que sean.

Encontramos una receta similar en la Félix PaLACIOS, op. cit. pág. 628, denominada también como Aceite de Myrrha, descrita de la siguiente manera: Tómanse los huevos cocidos, se parten por en medio y se quitan las yemas, en cuyo lugar se echa la myrrha en polvos. Se colocan en cazuela de barro y se dejan en lugar húmedo, deshaciéndose la myrrha en un licor que se guarda para su uso en tratamiento de putrefacción de humores y contra los vapores histéricos.
} 
R: Sabina, hierba que trayéndola consigo las mujeres, no conciben. La salvia caliente con alguna "astrición" hace a las mujeres fecundas si bebieren de su zumo ${ }^{44}$.

R: El romero, es caliente y seco, admirable para dolor cefálico y tos. Su cocimiento hecho en agua y dado a beber sana las aterciadas; su flor en conserva conforta el corazón, estómago y cerebro y restituye la memoria perdida. Saludable contra lo frío de estómago y cerebro ${ }^{45}$.

$\mathrm{R}$ : Tomillo, resuelve y conforta el cerebro pues es caliente y seco; su olor solamente restituye el sentido a los asidos de gota ${ }^{46}$.

- MAL GÁLICO ${ }^{47}$

R: Media libra de zarza se echa en 6 azumbres de agua con 4 onzas de pasas de lejias ${ }^{48}$, sin granos; media onza de sándalos colorados ${ }^{49}$, una onza de hojas de sen. Todo junto cuece en una olla nueva, vidriada, muy tapada hasta que quede en un azumbre ${ }^{50}$ de agua. Luego se cuela y se echa una libra de azúcar de pilón

\footnotetext{
${ }^{44}$ DioscóRIDES, op. cit. pág. 289: .. el cocimiento de sus hojas y ramas bebido, provoca la orina, el menstruo y el parto (...) Agripa la llamó hierba sagrada porque hace a las mujeres fecundas.

${ }^{45}$ Dioscórides, op. cit. pág. 321: El romero es caliente y seco en el segundo grado. Su sahumaro fija admirablemente a la tos, al catarro y al romadizo. Comida su flor en conserva conforta el cerebro, el corazón y el estómago. Aviva el entendimiento y restituye la memoria perdida (...) y en suma, es saludableremedio contra todas las enfermedades frías de cabeza y estómago.

${ }^{46}$ DioscóRIDES, op. cit. pág. 293: ...conforta admirablemente el cerebro y, con sólo su olor, restituye a sí mismos los asidos de la gota. Para tratar la gota, el recetario de Diego Bercebal, op. cit. ofrece el siguiente remedio que, aunque no tiene semejanza con el de Teixeiro en cuanto a su composición, es semejante en cuanto al origen y naturaleza de los elementos que lo conforman. Para la gota, el remedio de Bercebal es el siguiente: excremento de palomas, limpio y molido con leche o agua de rosas. Hacer un cataplasma y aplicarla en la zona a tratar. Por otro lado, encontramos otros remedios de naturaleza similar a los referidos por Teixeiro; como febrífugo, Bercebal propone un remedio a base de hollin, telas de araña limpias, parietaria y ortigas. Picar todo y rociar con vinagre aplicándolo como emplastos en las muñecas y tobillos. Vemos, pues, que las propuestas farmacológicas de Teixeiro no están fuera de un entorno sanitario particular desarrollado a lo largo del siglo XVIII.

${ }^{47}$ Mal Gálico, Mal napolitano o sífilis. Ya en 1497 el médico valenciano Gaspar Torrella, obispo y prelado doméstico de Alejandro VI publicó un tratado sobre el Mal Gálico, una patología que desencadenaba la formación de úlceras y pústulas dolorosas por todo el cuerpo después de contraer la enfermedad ex coitu cum impura muliere.

${ }^{48}$ Dioscórides, op. cit. pág. 506: ...unos meten los racimos recién cogidos dentro de lejía hirviente y se guardan.

${ }^{49}$ Según Dioscórides, existen tres tipos de sándalo, el cetrino, el blanco y el bermejo o colorado.

${ }^{50}$ Azumbre hace referencia a una antigua unidad de medida para volumen de líquidos que, en Castilla, equivalía a 2,5 litros. Estaba dividida en cuatro cuartillos que, en Galicia, recibían el nombre de Netos; así, cuatro Netos hacían un cuartillo. Félix Palacios, op. cit., pág. 177, ofrece una relación de pesos y medidas empleados en la época: un azumbre mayor equivalía a 4 libras de a 16 onzas de vino; se dividía en 4 cuartillos. Un cuartillo equivalía a 16 onzas. El azumbre menor equivalía a 42 onzas, mientras que la onza podía equivaler a 6 dracmas de aceite u 8 dracmas de vino.
} 
y unos polvos de canela. Se vuelve a la lumbre, donde cocerá y se irá espumando hasta que quede como un almíbar.

R: La grasa de la anguila puesta en candil hace que todo el aceite parezcan culebras.

R: Remedio para cualquier golpe que no se engendre apostema y conforta: tómese orégano ${ }^{51}$ y el agua donde cuece se cuela y después se le echa azúcar a la misma agua y vuelve a hervir y se bebe la dicha agua.

R: La margarita ${ }^{52}$ sirve, el zumo de ella tomada en agua de cardo o común, para fiebre maligna y pútrida, evacua por orina y sudor y en infusión quita en breve las tercianas y cuartanas. Para la piedra se hace infusión con ella. Partes iguales de hierba buena en agua de salsifras ${ }^{53}$ y se toma en ayunas antes de la cena.

Fui engendrado el año de mil 70 i 6, año de jubileo, a 2 de Marzo, mi padre caminando a 30 y mi madre a 10 i 8, mi padre con un barrunto de cólera y mi madre con resquicio de una calenturilla que a la mañana ya no había vestigios de ella, precedida de haberse llegado a demasiado fuego entre 8 y 9 de la noche y en lo seguro antes de la media noche fui engendrado;8 días anduve de más en el vientre de mi madre. Nací a 10 de febrero, año de mil 707 a las 4 de la tarde caminando desde la media al tercero ${ }^{54}$.

R: Para ejercitar la cólera, pólvora y si es de Murcia mejor, mezclada con agua ardiente, bebidos aumenta el valor ${ }^{55}$.

\footnotetext{
${ }^{51}$ Las hojas y sumidades floridas del orégano contienen un aceite esencial; su infusión se emplea como tónico estomacal y antiespasmódico.

${ }_{52}$ Margarita o Manzanilla (Chamaemelum nobile y Chamomilla suaveolens). En medicina se emplean tradicionalmente las cabezas florales como estomáquicas, antiespasmódicas y en tratamiento de meteorismo y flatulencias, sin evidencias de su actividad como antitérmica. Las fiebres que el autor denomina como putridas y malignas hacen referencia a la conocida entonces como fiebre pútrida maligna o petequial que hace alusión al tifus exantemático, enfermedad caracterizada por la aparición de fiebre, cefalea y exantemas, que hasta mediados del siglo XVIII era confundido en su descripción con la fiebre tifoidea o fiebre pestilente, distinguiéndose actualmente la Fiebre pútrida (tifus) de la Fiebre nerviosa lenta (tifoidea). Josef Alsinet en Nuevo método para curar flatos, hypocondria, vapores y ataques hystéricos de las mujeres de todos estados y en todo estado, Madrid, Miguel Escribano, 1776, reconocía que la enfermedad, aunque común, era poco conocida, recomendando para su tratamiento moderación en el uso de purgantes y control del uso de sudoríficos, recurriendo a remedios evacuantes, sangrías, tártaro emético, lavativas de agua y fomentos, según la fiebre pútrida fuera o no inflamatoria.

${ }^{53}$ Salsifrás = Sasafrás, aceite esencial de color amarillento, menos volátil que el agua y más denso.

${ }^{54}$ Así, intercalado en el texto se presenta el párrafo correspondiente a los datos biográficos de Anselmo Arias Teixeiro. Su padre, Pedro Arias, nacido en 1676, contaba 30 años en 1706 y su madre, Petronila, nacida en 1689 tenía entonces 17. Anselmo fue bautizado en la aldea de Banga el 17/02/1707.

${ }^{55}$ Polvora de Murcia es un término que hace referencia a la pólvora que se elaboró desde mediados del siglo XVIII en una fábrica de nueva construcción en la localidad de Jabalí Viejo (Murcia) ante la grave carencia de este producto, hecho que llevó al Gobierno a replantearse unas nuevas instalaciones que pudieran abastecer de pólvora de guerra al ejercito español. La fábrica de Jabalí Viejo, construida en 1633, fue de propiedad particular hasta 1747.
} 
R: Recipe mayorana ${ }^{56} 2$ qtos de hysopo $Z^{57}$, otro de cantueso ${ }^{58}, Z$ de almoraduj ${ }^{59}, Z$ de salvia, $Z$ de flor de romero, $Z$ de calamento ${ }^{60}, Z$ de melisa, $Z$ de cálamo aromático, $Z$ de betónica ${ }^{61}$. Todo eso se hace polvos y se echa en una libra de tabaco; después, se pone entre el tabaco una camuesa con 6 clavos finos metidos en ella ${ }^{62}$ después de haber estado 24 horas en un poco de vino blanco, y con este vino se rocía el tabaco.

-Polvos-

R: 2 onzas de zarza, una xg, media de polipodio, una de cantueso, media de fermodáctiles ${ }^{63}, 2$ qtos de azufre de canutillo. Todo esto se muele, cada cosa por sí y luego se mezcla $y^{64}$ se hace. Tómase así el almíbar como los polvos, dos horas antes del almuerzo a la mañana y 2 antes de la cena a la tarde. Se echan 3 cucharadas grandes de almíbar y una toma de polvos y se mezcla bien y, si estuviere espeso, se le echan más gotas de agua de zarza.

\footnotetext{
${ }^{56}$ Según Dioscórides, op. cit., la mayorana, almoradux o mejorana, Origanum majorana, sirve para retención de orina y retortijones de vientre. Es una planta aromática de la familia de las labiadas, muy usada en alimentación. Por su contenido en aceites esenciales se empleó tradicionalmente como sedante, espasmolítica e hipotensora, así como tónico estomacal y carminativo.

${ }^{57}$ Hisopo $\mathrm{Z}=1$ dracma de Hisopo, Hyssopus officinalis, planta de la familia de las Labiadas, empleada como purgante. Arbusto leñoso, originario de zonas mediterráneas, se utiliza en afecciones de garganta, bronquitis, asma, principalmente por sus efectos broncodilatadores.

${ }^{58}$ Cantueso = Lavándula stoechas, planta de la familia de las Labiadas. Arbusto de 1 metro de altura, frecuente en Extremadura, en bosques de encina y alcornoque, se usa como antiséptico para lavar heridas y llagas.

${ }^{59}$ DiosCóRIDEs, op. cit. indica que la mayorana también se denomina almoradux.

${ }^{60}$ Calamento o Cálamo = Acorus calamus, también llamado Cálamo aromático. Planta de la familia de las Araceas, crece a orillas de los pantanos y ríos de Europa. Su principio activo es un aceite localizado en el rizoma, preparado por cocción o tintura que se emplea como relajante muscular, sedante débil del sistema nervioso central o analgésico.

${ }^{61}$ Betónica = Stachys officinalis trevis. Planta de la familia de las Labiadas, típica del bosque europeo, usada como sedante, astringente y cicatrizante.

${ }^{62}$ La Camuesa, es el fruto del Camueso y, según indica Dioscórides, op. cit., es un tipo de manzana que Andrés Laguna, traductor de esa obra, sitúa únicamente en España.

${ }^{63}$ Fermodáctiles hace referencia a Hermodátiles, una raíz de forma parecida al corazón, de sabor dulce, procedente de la planta Iris tuberosa, usada en polvo hasta dosis de un dracma, o doble cantidad si se preparaba en infusión.

${ }^{64}$ El contenido de ésta y otras recetas contenidas en el manuscrito no parece ser fruto de los conocimientos médicos o farmacológicos de Teixeiro, atribuibles a alguien sin los conocimientos adecuados para tratar las patologías de la época; al contrario, responden a un tipo de medicina muy popular en su momento basada en el uso de remedios caseros al alcance del pueblo llano. Pedro de VIÑaburu en la Cartilla pharmaceutica chymico-galénica, Pamplona, Joseph Joachín Martínez, 1729, lo califica como "medicamento atrayente" y "de poderosa virtud".
} 
$\mathrm{R}$ : Regla ${ }^{65}$ que ha de guardar luego que se tomase, hace ejercicio y, si puede sudar, mejor. Prívase de toda carne de puerco, vino y sólo ha de beber agua de zarza en tan solo un puchero de gallina y carnero. Prívase de mujeres y lavarse con agua más que tibia, lo que ejecutará 6 días después de tomado el vomitorio ,que se da al cabo de 5 días en que, mañana y tarde, se toma la conserva y polvos, el cual vomitorio vienen a ser 2 o 3 granos de guftilio conforme a los rebrotes del sujeto. Efectos, a los 5 días se conoce grande mejoría. A los 9 se hallará totalmente bueno. A unos causa sudor y a otros cursos, y si debilita se puede suspender dos dias; puede tomarlo en pie, no siendo el tiempo muy frío no se ponga donde le dé mucho el aire y puede hacer un moderado ejercicio.

\section{-INCORDIOS ${ }^{66}$}

R: Palo santo, polipodio, zarza, 2 onzas de cada cosa; échase en 3 azumbres de vino blanco, bueno y también en el vino, una punta de cuerno de carnero de 3 dedos de largo y a las 24 horas se toma por la mañana medio cuartillo y se prosigue esto hasta 20 días; nota, que de las 2 onzas de zarza, la onza y media se echa en infusión.

R: Para flujo de sangre por la boca o vena rota ${ }^{67}$ : haz un vaso de fresno, echa en él vezadte puro, preparado seco al fuego y caliente, echado en el vaso y que

\footnotetext{
${ }^{65}$ Esta es una de las pocas recetas que encontramos descritas en alguna de las obras consultadas. Concretamente la refiere fr. Diego BERCEBAL op. cit. como remedio eficaz para "la cólera", similar utilidad que observamos en el manuscrito de Teixeiro. En su obra, Bercebal recomienda hacer ejercicio, no tomar carne de cerdo ni vino, tomar caldo de gallina y carnero, a la vez que insiste en "privarse de mujeres". También recomienda lavarse con "agua más que tibia" para conseguir la curación en un intervalo de nueve días, que en el caso de Teixeiro se reducen a cinco. La similitud de ésta y dos o tres recetas más nos lleva a pensar en que el manuscrito de Teixeiro se trata de una recopilación de recetas obtenidas de diferentes fuentes, sin descartar que algunas procedan directamente de su entorno en Cabanelas.

${ }^{66}$ En la obra del jesuita alemán Juan de EsteYNEFFER, Florilegio medicinal de todas las enfermedades, sacado de varios y clásicos autores, para bien de los pobres y los que tienen falta de médico, Madrid, Manuel Fernández, 1732, pág. 363, encontramos referencias al Encordio o Bubo, del que dice es un tumor o inflamación de las partes glandulosas, en particular de las ingles (...).Todos se hallan en las ingles, unos son críticos, otros sintomáticos, ya gálicos, ya pestilentes, recomendando como tratamiento, medicamentos que mitiguen el dolor, guardar dieta y aplicar aceite rosado, harina de cebada y raíces de malva o semillas, añadiendo polvo de manzanilla y mantequilla y dos yemas de huevo hasta hacer un emplasto que se aplicará sobre un lienzo varias veces. Por su parte, Pedro BIURETA, op. cit., propone como tratamiento para los encordios, colocar estiércol húmedo y fresco sobre un lienzo, espolvorear vidrio molido y aplicarlo sobre la zona a tratar. Juan CuRBo SEMmEdo, op. cit. propone como tratamiento diaquilón gomado, mezclado con jabón.

${ }^{67}$ Diego BerCeBAL, op. cit., refiere esta misma receta para tratar la misma patología, recomendando fabricar un vaso con madera de fresno sobre el cual se echará bezoar puro, escupiendo en él el paciente para sanar a continuación. Lo que Teixeiro refiere como vezadte puro hace referencia al referido bezoar puro. Se trata de un cálculo localizado en el intestino o estómago de algunos animales rumiantes para ayudarles durante la digestión, estando formado por pequeñas piedras, pelo
} 
escupa el enfermo en él y sana luego. Polvoriza después el vaso con polvos de hematitis ${ }^{68}$, piedra y entierra el vaso, unta la nuca al enfermo con aceite de nuez moscada cada 2 días.

R: Para cualquier dolor: toma un poco de levadura, un poco de cantáridas ${ }^{69}$, un poco de sal y con vinagre muy fuerte se hace un emplasto, se pone sobre el dolor, luego hace una vejiga, reviéntala y quedarás sano.

R: Para jaqueca: recipe confortante de Vigo ${ }^{70}$ y goma de limón ${ }^{71}$ y a falta de todo lo demás, la goma de limón sóla, que se pone todo en unos parchitos de tafetán en las sienes. Señal de gálico, una espontánea laxitud en todo el cuerpo y no puede abrir las manos ni cerrarlas sino con mucha pesadumbre, y las llagas salen a modo de callo, sin poder curarse con medicamento como las demás y suelen mortificar más de noche que de día.

etc. Tradicionalmente se le ha atribuido la propiedad de contrarrestar la acción de los venenos. Los polvos de hematitis referidos a continuación eran un remedio a base de oligisto, óxido férrico mineral de gran dureza, que se preparaba en forma de polvo, y que se utilizó también para decorar piezas de cerámica. La piedra hematitis la define J. J. PlencK, op. cit., pág. 152, como una mina de hierro, de acción desecante y corroborante, usada en tratamiento de úlceras mezclada con miel.

${ }^{68}$ Hematitis hace referencia a la Piedra hematites o Lapis hematites, sustancia ferruginosa, de sabor astringente, de la cual refiere Francisco CARBonell y BRAVo en Elementos de Farmacia fundados en los principios de la Quimica moderna, Barcelona, Imprenta de Manuel Texero, 1824 su procedencia alemana.

${ }^{69}$ Las Cantáridas son un tipo de insectos oblongos de color amarillo verdoso y de olor nauseabundo, normalmente se recurría a la especie Meloe vexicatorius, que se encuentra formando colonias en olivos, saúcos y álamos. Francisco CARBonell y Bravo, op. cit., indica que deben elegirse enteros, recientes y libres de polvo. J. J. PLENCK, op. cit., describe la Tintura de cantáridas, formada por las cantáridas y espíritu de vino, muy útil en "tumores blandos de las articulaciones" y en "dolor reumático", así como en la gonorrea, incontinencia urinaria e, incluso, como afrodisíaco. El principio activo responsable de su actividad terapéutica es la cantaridina, veneno potente que a lo largo del siglo XVIII ocasionó numerosas muertes por uso indebido de este remedio. Según Andrés LaGUNA, op. cit., 2 gramos de polvo de cantáridas podían ocasionar la muerte de un adulto. Muy habitual fue un remedio compuesto por levadura y cantáridas (una onza de la primera, polvo de cantáridas y media onza de vinagre, formando todo una masa). En la obra de A. J. L. Jourdan, Farmacopea Universal, Madrid, Imprenta de Fuentenebro, 1829, aún se refieren varios remedios a base de cantáridas.

${ }^{70}$ Hace referencia a un emplasto conocido como Confortativo de Vigo. En Dioscórides, op. cit. pág. 542: Juan de Vigo (...) azogue calcinado con aguafuerte para consumir sin dolor toda carne superflua. Juan de Vigo (1460-1520) ideó varios emplastos a base de mercurio y ranas, siendo defensor del uso de aceite hirviendo para cauterizar heridas por armas de fuego.

${ }^{71}$ Goma de limón o Gummi elemi, es una resina natural, untuosa, que se extrae del tronco del árbol Canarium luzonicum o del Amarys elemifera. Aparece referido en ocasiones como "ungüento de goma de limón compuesto" en diferentes obras, entre otras, la de J. J. PlencK, op. cit., que lo denomina "ungüento goma Limón", usado conjuntamente con trementina y aceite como digestivo y para "mundificar las úlceras", o en Lucas Alamán, Apéndice al Diccionario Universal de Historia y Geografía, Méjico, Imp. F. Escalante, 1856, donde señala que "es planta de la Carolina (...) que viene en una massa sólida de color amarillo verdoso, de donde toma el nombre, por ser parecido al limón”. 
R: Para dolor de muelas: orinas de buey todo negro echadas en la boca, pasan, y no hay remedio como el; a falta de esto se pide en la botica 2 qtos de filonio romano ${ }^{72}$ y se le da a la encía por la parte de adentro y fuera con él y si está horadada y hay pimienta larga se coge un grano de ella y la mitad se entra en el agujero y alivia el dolor luego.

Los libros de plantas, Escrodro 2 tomos $^{73}$, 330 pesos, Dioscórides ${ }^{74}$, Bigier $^{75}, 3$ tomos y uno de cirujía, Montaña ${ }^{76}$. 16 libros intitulados Descollas de

${ }^{72}$ En la obra de Bercebal, op. cit., encontramos esta receta para el dolor de muelas, apareciendo descrita de la siguiente manera: Orinas de buey todo negro en la boca; sino, pedir en la botica filonio romano para aplicar en la encía. También un grano de pimienta si es que hay orificios en la dentadura. Tradicionalmente se han empleado las orinas de animales en la terapéutica, entre otras se citan las de toro, la de muchacho impúber, de castor, de borriquillo o la humana. El Filonio romano es un electuario romano para tratar el cólico o disentería, aunque también existen referencias a su uso como somnífero y en tratamiento de apostemas y úlceras, formulado a base de opio, miel, etc. Por su parte, M. A. Marcos CASQuero, en "Virtudes mágicas y medicinales de la orina según los escritores latinos", Revista de la Universidad de León (2005), disponible en <http://hdl.handle.net/10612/577/> [Consulta: 22/02/2015], refiere el uso de orina de buey en la localidad de Guadramiro (Salamanca) como enjuague para la boca en casos de dolor de muelas.

${ }^{73}$ Escrodro o Escrodero, su nombre oficial es Johann Schroeder, (1600-1664), autor de la Pharmacopoea medico chymica, editada en numerosas ocasiones a lo largo de los siglos XVII y XVIII. Sin embargo, Félix Palacios, op. cit. pág. 106, al tratar de De la Pharmacia en general, no cita la Schröder (Escrodero) entre las farmacopeas de referencia sino entre los libros de plantas.

${ }^{74}$ Pedacio Dioscórides Anarzabeo de Materia Médica, es como se conocía la obra de Dioscórides, a cerca de la materia medicinal y los venenos mortíferos.

${ }^{75}$ Bigier $=$ Jean Vigier, farmacéutico francés residente en Portugal, fue autor de varias obras de farmacología: Tesouro apolineo químico-galénico-farmacéutico, Lisboa, Off. Real Deslandesiana, 1714; es un tratado de terapéutica dedicado a los medicamentos de origen químico, Pharmacopeia Ulyssiponense, galenica e chymica que contem os principios, diffinicoens e termos Gerais de uma \& outra pharmacia, Lisboa, Francisco Borges de Sousa, 1716, que fue el primer manual de química farmacéutica impreso en portugués, a inspiración del Cours de Chymie de Nicolás Lemery. Es autor, también, de una Historia de las plantas de Europa e das mas uzadas que vem de Asia, de Affrica \& da America, onde vese suas figuras, seus nomes, em que tempo florecem e o lugar onde nacem, Lyon, Anisson, Pousel \& Rigaud, 1718, compendio de plantas, sus usos, propiedades, descripción y denominación en varios idiomas, descritas de forma breve y sencilla. Vigier llegó a Lisboa a finales del siglo XVII para trabajar en la botica de su tío, estableciéndose finalmente en la ciudad.

${ }^{76}$ Podría hacer referencia a la obra de Bernardino Montaña de Montserrate, Libro de anatomía del hombre, juntamente con una declaración de un sueño que soñó el Ilmo.Sr. D. Luis Hurtado de Mendoza, Marqués de Mondejar, Valladolid, Imp. Sebastián Martínez, 1551. Se trata de la única obra conocida de este autor, catedrático de la Universidad de Valladolid y uno de los médicos del Emperador Carlos I. La obra, descrita por J. L. Barona, La Ilustración y las Ciencias. Para una historia de la objetividad, Valencia, Publicaciones de la Universitat de Valencia, 2003, es un estudio sobre el sistema de circulación de la sangre, aportando además teorías sobre anatomía y fisiología del sistema nervioso. Se trata, pues, del primer tratado de anatomía editado en lengua castellana, en la línea del galenismo de la época pero con algunos aspectos novedosos, ajenos al galenismo clásico. Incorpora, además, descripciones del concepto de Quintaesencia, describiendo un tipo de agua ardiente con propiedades para la salud. 
cirugía y medicina y la forma séctica de boticarios. Todos 330 pesos. Silva ${ }^{77}$ de experiencias, curioso libro Zapata ${ }^{78}$ de boticarios rico. Libro el más curioso de botica de Zapata.

R: Para sacar la piedra a los dientes y limpiar armas, cógese una piedra de grano y se pone en el horno hasta tanto que le pase el fuego que será cuando se deshiciesen con las manos, estregándola entre ellas, luego se le da con un poco de agua de rosas y estregando con ella los dientes los pone muy blancos y les saca las piedras, y a las armas las deja muy lucidas.

Las espadas, estoques, verduguillos ${ }^{79}$ que tuvieran en la hoja una C luego una coma después, luego siguiere a la coma una estrella, a la estrella siguieran 3 puntos seguidos y luego tuvieran unas letras que digan "tole" y al fin 5 rayas, a manera de escudo, buenas, pues son las mejores y más antiguas. De estas siguen las que tuvieran 2 rayas, luego digan Toledo claro y al fin una O que significa el mundo, y estas son de segunda especie, como las que tienen media $O$ de tercera $y$ de todas estas los verduguillos que tienen al medio una cota, como navajas de barba, son los mejores.

R: Para calenturas al tiempo de entrar el frío se cortan la uñas y se dan a comer en un poquito de pan a un perro.

$\mathrm{R}$ : Para dolor de muelas se saca un diente a un perro vivo y se trae consigo y cuando duele se aplica.

\footnotetext{
77 Silva de experiencias hace referencia a la obra de Luis LoBerA, Remedio de cuerpos humanos y silva de experiencias y otras cosas utilisimas; nuevamente compuesto por el excellentissimo doctor Luís Lobera de Avila, Alcalá de Henares, Juan de Brocar, 1542. Lobera fue médico de Carlos I y redactó esta obra en la que presenta una serie de remedios para dolores, epilepsia, enfermedades y diferentes afecciones del organismo.

${ }^{78}$ Podemos suponer que se trata de una de estas obras: Luis ZAPATA, Miscelánea. Silva de casos curiosos, Madrid, 1592, o la obra de Giovanni Battista ZAPATA, Il maravigliosi secreti di medicina e chirugia nuovamente ritrovati per guarire ogni sorte d'infirmitá, raccolti dalla prattica delléxcellente medico M.Gio.Battista Zapata, da Gioseppe scientis chirurgico, suo discepolo, Turín, 1581. También podría hacer referencia al médico Diego Mateo Zapata (1664-1745), perteneciente al grupo de los novatores o precursores de la nueva mentalidad científica del siglo XVIII español. Efectivamente, algunas de sus obras tuvieron gran interés para los boticarios, tal como describe el texto de Teixeiro, quizá la Crisis médica sobre el Antimonio, Madrid, s.n., 1701, obra en la que defiende los estudios de Schröder sobre el antimonio (sulfuro de antimonio), reconociendo el trabajo de muchos "filósofos que han intentado sacar por el Antimonio, de metales imperfectos el perfecto".

${ }^{79}$ El verduguillo es un tipo de puñal de perfil muy fino que provocaba una herida apenas perceptible pero profunda. Había otros modelos, más largos y del grosor de un dedo meñique. La hoja del verduguillo, de sección cuadrangular o romboidal se correspondía con varios de los espadines empleados a mediados del siglo XVIII, con una longitud de hoja variada pero que podía alcanzar los 1012 x 15 mm, disponiendo además de una acanaladura central en su primer tercio. Fue un tipo de espadín derivado de las pequeñas espadas del siglo XVII denominadas roperas.
} 


\section{R: Para la madre se toma zaumeris ${ }^{80}$ por debajo de los pelos del empeine del hombre ${ }^{81}$.}

$\mathrm{R}$ : Para dormir, recipe philonio romano, drag.j ${ }^{82}$ con agua de borrajas, se desate y si no bastare esta cantidad, tomado cuando se va a acostar al otro día le dan dragma y media.

R: Para hermosear el rostro y las manos, recipe miga de pan blanco, lib. iiij ${ }^{83}$, flores de habas, rosas blancas, flores de nenúfar, de lirios blancos, an lib. $i j^{84}$, leche de vacas, lib. vj ${ }^{85}$, huevos, lib. viij ${ }^{86}$, vinagre blanco escogido lib.j $j^{87}$; destílese todo junto, en alambique de vidrio y sáquese el agua para el rostro y las manos y lávese con ella de noche, que es de mucha estima.

R: Ungüento admirable para la sarna: manteca de vacas, un g.vj ${ }^{88}$, trementina, un g.iij ${ }^{89}$, solimán drag $i j^{90}$, zumo de limón una lib. vj ${ }^{91}$, tráigase en mortero de piedra y añádase poquito estoraque líquido, es muy experimentado.

R: Para la voz, flor de saúco, seca a la sombra ${ }^{92}$.

$\mathrm{R}$ : Media dragma o 2 escrúpulos de destilación simple de cangrejo, medicamento excitante en gran manera ${ }^{33}$ a lujuria, con este medicamento de levante.

\footnotetext{
${ }^{80}$ Podría hacer referencia a los inciensos o sahumerios.

${ }^{81}$ Debemos entender aquí como empeine del hombre una enfermedad del cutis por la cual éste se vuelve áspero y encarnado, causando picazón. Posiblemente hace referencia a todo tipo de dermatitis, psoriasis y eccemas. Biureta, op. cit., propone como tratamiento la ruda, con miel y alumbre.

${ }^{82}$ drag $\mathrm{j}=1$ dracma

${ }^{83}$ lib.iiij $=4$ libras

${ }^{84}$ lib.ij $=2$ libras

${ }^{85}$ lib.vj $=6$ libras

${ }^{86}$ lib. viij $=8$ libras. Fue muy habitual el uso de huevos en la terapéutica del siglo XVIII, ya cocidos o como aceite de huevos, Oleum ovorum, yemas de huevos cocidos y tostados usado como emoliente y demulcente en quemaduras y, según J. J. PLENCK, op. cit., en almorranas dolorosas, grietas en los pezones, labios o genitales.

${ }^{87}$ lib.j = 1 libra

${ }^{88} \mathrm{~g} . \mathrm{vj}=6$ granos

${ }^{89}$ g.iij $=3$ granos

${ }^{90}$ drag $\mathrm{ij}=2$ dracmas

${ }_{91}$ lib.vj $=6$ libras

${ }^{92}$ Saúco, Sambucus nigra, arbusto empleado hoy en día como expectorante.

${ }^{93}$ Muy utilizados, más que el destilado de cangrejo, fueron los llamados Ojos de cangrejo u Oculi cancrorum, unas concreciones de naturaleza calcárea, duras y blancas que se hallan pegadas entre las túnicas del estómago de los cangrejos de la especie Cancer astacus, que habita en algunos ríos de Europa. Ignacio Andrés ArRiBAs, en Relación de simples de la Botica del Hospital Real y general de Nuestra Señora de Gracia de Zaragoza (1425-1808), Tesis doctoral, [en línea], disponible en $<$ http://biblioteca.ucm.es/tesis/19911996/D/1/AD1002501.pdf/> [consulta: 12/01/2015], encontramos remedios similares a los descritos por Teixeiro a lo largo de este manuscrito; entre otros, antimonio crudo, azogue, ojos de cangrejo, cangrejos preparados, cinabrio nativo, coloquíntidas, cuerno de ciervo raspado, goma de limón, mercurio dulce, mirra, piedra hematites y solimán. En el inventario
} 
Parches de vinagre aplicados en los intestinos y vientre, mitigan mucho por lo frío que es; maluco ${ }^{94}$, palo tan fuerte como el acero, da un fruto como avellanas, que tomado en poca cantidad, incita a lujuria y en mucha, a profundo sueño. Para infundir sueño la hiel de lebracho, suelta en el caldo. Para quitar manchas de ropa, la hiel de carnero, estregando la mancha con ella.

Señales de conocer una mujer virgen: cuando ve al hombre, la mujer doncella clava en él los ojos muy alegres, labios encarnados, pechos cortos y no caidos, antes bien llegados. La que no, cuando ve al hombre baja los ojos, los pechos grandes y caídos, los ojos tristes y no clavados. Si está preñada se ha de reparar si es de caderas anchas o cortas, si de anchas, a cuatro dedos andando al vientre desde las caderas en aquel ojo que hace alli el vientre. Se ha de mirar si está crecido el dicho ojo cosa de 2 dedos o igual con la cadera y si está fuera. Si es de caderas angostas, luego mirar el vientre, como también si se aparece algún paño en la cara, o si tiene el pulso débil o con un poquito de calambres.

Para conocer si me han dado veneno, si la lengua se siente áspera y negra al acabar de tomar, señal cierta de que me han dado veneno, luego triaca y, a falta de ésta, se modera con manteca y aceite, sal, pimienta y vino en cantidad, todo junto vuelven a un individuo loco y esto se regula: sudar beber agua y arrojarla y horchatas.

$\mathrm{R}$ : Para lombrices, eficaz remedio excremento de cerdos cocido con vinagre puesto en el vientre; en enfermedad gálica no se sangra.

R: Dar zumo de beleño, de zeguta ${ }^{95}$, de mandrágora, de pocmictras ${ }^{96}$ y que estos zumos se envuelvan en una esponja nueva, la cual, después de seca al sol,

del mismo hospital, realizado en 1767, aún encontramos cantáridas, asta de ciervo, ojos de cangrejo, piedra bezoar, vitriolo y mercurio dulce, entre otros.

${ }_{94}$ Maluco o Genipa americana, es un árbol cuya fruta es una nuez muy cáustica. La semilla contenida en dicho fruto es comestible, según algunas fuentes de la época, mezclándola con cacao para hacer el chocolate. El árbol, cuya madera es muy dura y pesada, se desarrolla desde Méjico hasta Brasil. ${ }_{95}$ Cicuta. En Dioscórides, op. cit., aparece también como Ceguta. Francisco Carbonell y Bravo, $o p$. cit., la recomienda en extracto, en dosis de un grano hasta un dracma, en fomentos y emplastos y J. J. PLENCK, op. cit., la califica como resolutiva, anodina y diurética, usada en escrófulas, úlceras y gonorrea. Esta receta la encontramos también en EsteYNEFFER, op. cit., que emplea zumo de beleño, cicuta y mandrágora para dormir al enfermo y, luego, para despertarlo, el zumo de hinojo. El beleño contiene un principio activo, la hioscina, con propiedades hipnóticas e inductora de un sueño de tipo narcótico. Esta receta, a base de beleño, cicuta, mandrágora y pocmictras no responde a una iniciativa particular del autor del manuscrito ya que la hemos encontrado en varias fuentes originales de la época. Se embebía una esponja con el jugo de estas plantas y se le daba a oler al enfermo para inducir el sueño. Guy de Chauliac (1298-1368), cirujano de la escuela de Montpellier, utilizaba ya esta esponja denominada esponja somnífera o esponja anestésica, a la que recomendaba añadir opio. Se dejaba secar la esponja al sol para su conservación y cuando se necesitase su uso se empapaba de nuevo y se aplicaba a la nariz. Es un remedio medieval cuya primera mención aparece ya en la Escuela de Salerno y, posteriormente en el Antidotarium Salernitatum, de Nicolás Praepósitus, un 
se meta en agua caliente para que la huela el enfermo hasta que se duerma. Hecha la obra, manda apretar otra esponja de otra virtud, mojada en zumo de hinojo caliente puesta a las narices para que despierte. Dioscórides: partes de mandrágora cocidas en vino, de bebida para que en un vaso, de media onza de Antimonio, 4 onzas de vino blanco, estará 24 horas, al cabo de las cuales que esté en dicho vaso, se tomará de allí a 2 horas el caldo ${ }^{97}$. Beberá agua de zarza mezclada con china y si bebe vino templado con dicha agua, púrgase antes que con la purga de antimonio, y esto lo hará 4 a 8 mañanas, conforme la necesidad, que hará provocar todo el humor a vómito y calmará, hará doler el vientre y, cuanto a la cantidad de vino, si llega a 20 años se le puede, seguramente, las 4 onzas, y esto se ejecuta en hombres robustos y fuertes y si el vino es de malvasía todo lo reducirá a cámara.

R: La miel, principalmente llamada virgen, aquella sacada de los enjambres nuevos, es un tesoro de ricas virtudes derivadas de todas las plantas y hierbas cuyo jugo se halla en ella. Destilada, es magnética, según Feijoo lo dice. Con la castellana, que llaman miel blanca, tomada en ayunas dice Zúniga que, al cabo de cuatro mañanas le habían pasado unas cuartanas porfiadas ${ }^{98}$. Vieite dijo que había curado cuartanas y tercianas y otra cualquier enfermedad y llagas, pero sin beber agua, apagando la sed con tostadas de pan mojadas en vino.

R: Remedio para conservar el vino incorrupto: echar dentro de la cuba tres granos gruesos de mirra o de incienso o de almastiga ${ }^{99}$. Los tres granos gruesos son tres lágrimas de cualquiera de las especies dichas, conforme salen del árbol sin pisarlas.

formulario de recetas médicas del siglo XII donde se dice lo siguiente: Tomar opio tebaico, jugo de beleño, bayas de mora todavía verdes, granos de lechuga, jugo de cicuta, adormidera, mandrágora, yedra (...) metédlo todo en un recipiente y sumergir alli una esponja de mar (...) dejad esto al sol durante los días de canícula. Cuando tengáis necesidad de ella humedecedla con agua no muy caliente y ponedla bajo las narices del enfermo. Si deseáis despertarle, aplicadle el jugo de la raíz del hinojo, en Manuel Barberá Alacreu, Pasado, presente y futuro de la anestesiología, 2003, [en línea], disponible en $<$ http://www.ramcv.com/Discursos/Dr.\%20Barbera.pdf/> [consulta: 18/01/2015].

${ }^{96}$ Pocmictras hace referencia a un tipo de manzana espinosa o al estramonio, Datura estramonium.

${ }^{97}$ Efectivamente Dioscórides, op. cit., refiere una receta similar. En la edición de 1555 leemos (pág. 423): algunos cuecen las raíces en vino (...) después cuelan el cocimiento y lo guardan. Se les da a los que no pueden dormir o padecen algún dolor.

${ }^{98}$ Francisco CARBonell y BRAVo, op. cit., prefiere la blanca o amarilla, indicando como la mejor la de Narbona, que debe ser aromática y de gusto agradable.

${ }^{99}$ Almastiga o Almaciga es una resina amarillenta y aromática que se extrae de una variedad de lentisco. 
R: Remedio contra el mal de piedra: toma gusanos que dicen ciempiés ${ }^{100} o$ de los gusanos que comen el palo; quémalos en una olla y dálos hechos polvos a beber al enfermo, que al instante se deshace el cálculo.

Por último plantea la posibilidad de crear un medicamento tal que pudiera modificar y corregir la falta de pasión o fuerza en los corazones débiles. Hace referencia a las pasiones, que podríamos entender como "cualidades humanas", fácilmente controlables y enmendables, en su opinión, afirmando que la impericia puede corregirse con la ciencia, es decir, con el estudio, frase que representa, a nuestro modo de ver, su actitud vital. Por otro lado, reclama también la prudencia y la observancia; es importante esta última proclama, que reivindica la observancia, el estudio y la prudencia, ya que nos sitúa en una posición claramente ilustrada, pero echamos en falta la experimentación, sin la cual el método científico no podría alcanzar sus objetivos. Efectivamente, Teixeiro observa y estudia pero no da el último y decisivo paso de experimentar aquello que observa; elabora él mismo sus propias argumentaciones basándose en sus observaciones y en lo que otros han escrito y ello limita, al fin y al cabo, todos sus estudios y argumentaciones, como hemos visto a lo largo de este trabajo. Defiende, además, que aquellas cualidades que dependen de los sentidos (podríamos entenderlos más bien como sentimientos) que emanan del corazón, son difíciles de corregir por medio de la razón y se lamenta, finalmente, de aquellos que poseen un corazón pobre y de los que carecen de ciencia o conocimiento de sí mismos. En este sentido, defiende la utilidad de la ciencia "y más la costumbre ordenada y aún forzada del conocimiento". Reclama, pues, una postura científica en cada uno de nosotros, acostumbrando o enseñando a razonar y fomentando el conocimiento científico de manera natural o forzada.

Finalmente y como contrapunto a lo anterior, se plantea la búsqueda de una panacea médica, remedio natural o medicinal que pudiera compensar el vacío que dejan las ciencias, expresándose en los siguientes términos:

\footnotetext{
${ }^{100}$ CARBonell y Bravo, op. cit., incorpora los gusanos “milpiés" o Assellus, denominados por Linneo como Onicus asellus, indicando que deben elegirse los más grandes, negros y que se encojan con facilidad formando un cuerpo redondo. Respecto a las lombrices de tierra, recomienda que sean del grueso de una pluma de escribir, de longitud de un dedo, blandas, carnosas y sin olor particular. J. J. PlencK, op. cit., lo define como gusano de cuevas o sótanos, útil como "atenuante" y diurético, así como en algunos problemas oculares como las cataratas, en los tumores de pecho y en las escrófulas. Se "exprime el zumo de cien cochinillas y se toma en una libra de caldo", afirmando que el polvo es menos eficaz.
} 
Las pasiones pertenecientes a las potencias capitales, como a la conciencia, prudencia, discurso, etc, son sujetas y fáciles de dominarse y enmendarse con el consejo, tiempo, estudio y cuidado, porque la impericia se puede ahuyentar con la ciencia y estudio; la prudencia con el tiempo, doctrinas, prudencia y observancia y así de las demás, pero las pasiones, que asientan en el apetito sensitivo radicado por orden de naturaleza en el corazón, son muy difíciles de soldar y curar por la razón, cuyo reflejo es siempre necesario en cada acción por no ser fácil el criar hábito deducido de la prudencia. Pobres de aquellos a quienes manda un corazón pobre, a quien no puede enfrentar la carencia de la ciencia o el conocimiento de sí mismos en cuanto tales. Mucho podrá hacer en esto la ciencia y más la costumbre ordenada y aún forzada del conocimiento. Quiero decir que se indaguen remedios naturales y medicinales que fortifiquen y aquilaten la temperie del tal corazón destemplado. Es cierto que los remedios de Hipócrates se aventajarán a los de Séneca.

\section{Conclusiones}

El autor, en definitiva, ofrece un texto para servir de manual terapéutico o, podríamos decir, de manual de primeros auxilios; se trataba de disponer de un texto que ofreciese un amplio abanico de fórmulas o remedios sanitarios para todo tipo de males. Se encuadra, por ello, en un tipo de obra relativamente frecuente en la historia de la terapéutica, principalmente en los siglos XVII y XVIII, en la línea de los recetarios de medicamentos, muchos de los cuales circulaban de manera manuscrita, como el ejemplar que presentamos en este estudio. A mediados del siglo XVIII comenzó a circular un tipo de obra similar pero más avanzada desde el punto de vista sanitario, los formularios de medicamentos, dirigidos a un público con mayor formación sanitaria; podríamos situar el texto de Teixeiro entre aquellos antiguos recetarios y estos nuevos formularios, entendiendo, por ello, que su contenido no supone un anacronismo histórico sino una realidad en la primera mitad del siglo XVIII.

\section{BIBLIOGRAFÍA}

Alamán, Lucas, Apéndice al Diccionario Universal de Historia y Geografia, Méjico, Imp. de F. Escalante, 1856.

Alsinet, Joseph, Nuevo método para curar flatos, hipocondría, vapores y ataques histéricos de las mujeres de todos estados y en todo estado, Madrid, Miguel Escribano, 1776. 
Álvarez Soaje, Miguel, Antonio y Anselmo Arias Teixeiro. Dos lulistas gallegos en el siglo de la Ilustración, Tesis doctoral inédita, Santiago de Compostela, USC, 2012.

Álvarez Soaje, Miguel, "Elaboración do viño do Ribeiro según un manuscrito do século XVIII", Boletín das Ciencias, 21, núm. 66 (Nov. 2008), págs. 181-182.

Andrés Arribas, Ignacio, La Botica del Hospital Real y general de Nuestra Señora de Gracia de Zaragoza (1425-1808). Tesis doctoral [en línea], disponible en $<\mathrm{http}: / /$ biblioteca.ucm. es/tesis/19911996/D/1/AD1002501.pdf/> [consulta: 12/01/2015].

Barberá Alacreu, Pasado, presente y futuro de la anestesiología, 2003 [en línea], disponible en $<$ http://www.ramcv.com/Discursos/Dr.\%20Barbera.pdf/> consulta: 18/01/2015].

Barona, J.L., Moscoso, J., Pimentel, J., La Ilustración y las Ciencias. Para una historia de la objetividad, Valencia, Publicaciones de la Universitat de Valencia, 2003.

Bercebal, Diego, Recetario medicinal espagírico. Obra posthuma de Fr. Diego Bercebal, enfermero Mayor del Real Convento de S. Francisco de Zaragoza, 1734.

Biureta, Pedro de, Libro de Medicina y remedios de las enfermedades por orden alfabético. Sacado a luz de diferentes autores y en particular del B. Gregorio López, Madrid, Juan García Infanzón, 1703.

Carbonell y Bravo, Francisco, Elementos de Farmacia fundados en los principios de la Química moderna, Barcelona, Imprenta de Manuel Texero, 1824.

Cardiel, Jesús, "La botica de Castejón de Sobrarbe en el siglo XVIII", en Revista el Gurrión, 103 (2006), págs. 6-14.

Consello da Cultura Galega, "Anselmo Arias Teixeiro", en Album da Ciencia [en línea], disponible en $<$ http://culturagalega.gal/albumdaciencia/detalle.php?> [consulta: 01/02/15].

Curbo Semmedo, Juan, Secretos médicos y chirurgicos del doctor Don Juan Curbo Semmedo, Madrid, Juan de Zúñiga,1735.

Dioscórides, Acerca de la materia medicinal y de los venenos mortiferos, Salamanca, Mathias Gast, 1566 [Edición facsímil, Fundación Ciencias de la Salud, 2005].

Esteyneffer S.J., Juan de, Florilegio medicinal de todas las enfermedades, sacado de varios y clásicos autores, para bien de los pobres y los que tienen falta de médico, Madrid, Manuel Fernández, 1732.

Flandes, fr. Luis de, El antiguo académico contra el moderno scéptico, o dudoso, rígido o moderado. Defensa de las ciencias y, especialmente de la Physica Pytagórica y Médica en el conocimiento y práctica de los Médicos Sabios, tomo I, Madrid, Imprenta del Reyno, 1742.

García Martínez, Antonio Claret, "La enfermería franciscana en el siglo XVIII. Recetario medicinal espagírico (1713) de Diego Bercebal. Estudio y edición", Hiades, revista de Historia de la Enfermería, 9 (2004), págs. 655-774.

Hispano, Pedro, Libro de Medicina, llamado thesoro de pobres, en que se hallarán remedios muy aprobados para la sanidad de diversas enfermedades, con un regimiento de sanidad. Compuesto por el Maestro Julián, que lo recopiló de diversos autores... Pamplona, Imprenta de Francisco Picart, 1727.

Laguna, Andrés, Pedacio Dioscórides Anazarbeo, acerca de la Materia Medicinal y de los venenos mortíferos, Salamanca, 1566 [Ed. Facsímil, Barcelona, Fundación de Ciencias de la Salud, 2005]. 
Lobera de Ávila, Luis, Remedio de cuerpos humanos y silva de experiencias y otras cosas utilisimas; nuevamente compuesto por el excellentissimo doctor Luís Lobera de Avila, Alcalá de Henares, 1552.

López, Gregorio, Tesoro de medicinas para diversas enfermedades, Madrid, Imprenta de Múgica, 1708.

Marcos Casquero, M.A., "Virtudes mágicas y medicinales de la orina según los escritores latinos", Revista de la Universidad de León (2005), disponible en $<\mathrm{http} / / \mathrm{hdl}$.handle. net/10612/577/> [Consulta: 22/02/2015].

Masdevall, Josef, Relacion de las epidemias de calenturas pútridas y malignas que en estos últimos años se han padecido en el Principado de Cataluña y principalmente de la que se descubrió el año pasado de 1783 en la ciudad de Lérida, Llano de Urgel y otros muchos corregimientos y partidos, con el método ... de curar semejantes enfermedades, Madrid, Imprenta Real, 1786.

Palacios, Félix, Palestra Pharmaceutica chymico galenica, en la cual se trata de la elección de los simples (...), Madrid, Joaquín Ibarra, 1763.

Plenck, J.J., Farmacología quirúrgica o ciencia de medicamentos externos e internos, Madrid, imprenta de Villalpando, 1805.

Suñé Arbussá, José $\mathrm{M}^{\mathrm{a}}$, Formularios de hospitales españoles. Siglos XVII y XVIII, Granada, Universidad de Granada, 2005.

Tissot, Mr., Tratado de las enfermedades más frecuentes de las gentes del campo, Madrid, Pedro Marín, 1790.

Vidós, Juan de, Medicina y cirugía racional y espagírica, Zaragoza, Gaspar Tomás Martínez, 1691.

Viñaburu, Pedro, Cartilla pharmaceutica chymico-galénica, Pamplona, Joseph Joachín Martínez, 1729. 